البحث رقم (r) - (ب) - (ب)

\title{
الشفافية كقيمة تشكيلية في فن النحت
}

\section{Transparency As a Formative Value In The Art Of \\ Sculpture}

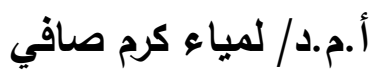 \\ أستاذ النحت المساعد- كلية التربية النوعية - جامعة كفرالثيخ
}




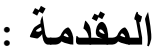

تعتبر الثفافية من القيم التشكيلية التي نظهر في مختلف الفنون لمنح العمل الفني لمسه جمالية تؤثز بشكل إيجابي علي المشاهد ، وفن النحت من أكثر الفنون التي استغلت الثفافية بأثـكال مختلفة ، وذلك لأنها تقدم حلول تشكيلية متتوعة تشبع رغبة النحات في التعبير وتوصيل أحاسيسه وأفكاره الإبداعية ، ولكل نحات أسلوبه الخاص مما فتح باب لإثراء عالم الفن بمنحوتات ذات قيمة نتكيلية عالية . وبتتبـع الثـفافية في فن النحت لوحظ وجودهـا علـي مـر العصـور بصـور متعددة ومنتوعـة ، و أضفت الثفافية علي أثنكال النحت المتعارف عليها قيمـة جديدة مبتعدة عن الكتلـة المصمتة ومـع تطورات الخامـات بعد ذلك ظهر مـا عرف بنحت الهواء أو الدخان المجد والتلج ، والثفافية وتمنح نوعا من الإحساس البصري بانعدام الوزن والهوائية ، وتسمح باتصال داخل العمل مع خارج العمل الفني.

كما شوهيد نماذج من أعمال النحاتين مثل موهولي ناجي، وناعوم جابو ، وظهرت مفاهيم جديدة أثرت علي العملية الابداعية وبالتالي أثرت علي تتوع الثفافية ،" فبظهور مفهوم الغاء الكتلة سعي الفنانين في بدايـة القرن عثرين إلي استخدام الفراغ كقيمة في العصل، حيث نقل كثافة المـادة، كما في أعمال المستقبلية التي أرتبطت بنظريـة النسبية (لأنشتاين) والتي غيرت مسار الفن، والتي تمنلت في ظهور الحركة في النحت، وتلتها أعمال البنائين حيث استخدموا عناصر مسطحة ذات بعدين، سواء كانت من خامات معدنية أوشفافة وذات بعد واحد بتقنيات كالتركيب واللحام والتعشيق، والتي تتناسب مـع هذه الخامـات المستحدثة،

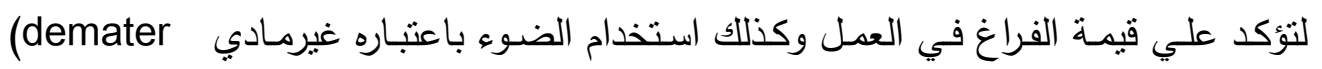
متمثنا في وحدات الضـوئية متحركـة كلمبات النيون والفلورسنت المتبادلة في 
الاضـاءة وكذلك التعبير عنها من خـلال حركة الضـوء التي تعمل علي تحرير الجسم من الجاذبيـة الارضـية وتحريـرا كليـا" i، بـالتطور الامـر إلـي الوصـول إلـي النحت الرقمـي وعلـم البرمجة واستخدم الفن تلاك العناصر كخامات تشكيلية.

ولذلك هدف البحث لتتاول مجموعة من الأعمال النحتية بالدراسة والتحليل سعيا لتعرف علي الأثكال المختلفة التي تتاول فيها النحات الثفافية من خلال خامات النحت المختلفة ، وظهر أهمية البحث في كونه يساهم في توضيح دور الثفافية كقيمة تشكيلية في منح العمل الفني

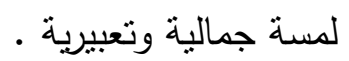

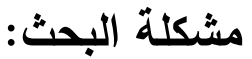

تحــددت مثـــكلة البحـــث فـــي محاولـــة دراســـة الثـــفافية وكيــــ أتـــرت

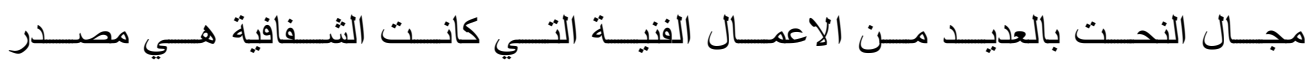

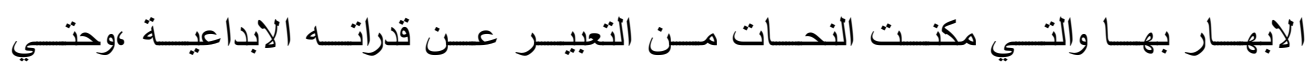
نتحقق من ذلك لنصل إلي هدفنا وجب علينا طرح التساؤل التالي: - ماهي ابعاد ومضمون فكرة الثفافية وعلاقتها بالثكل النحتي ؟ - كيف تمكن النحات من الاستفادة بالثفافية كقيمة تشكيلية في اثراء فن النحت؟

\section{هدف البحث:}

- - دراسة بعض الاعمال الفنية لاستخراج المتغيرات الفنية التي حدثت بفعل الثفافية

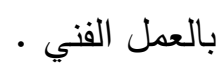

- - التعرف علي انواع الثفافية التي استخدمها النحات والاسباب التي جعلت من الثفافية تتحولة إلي ومضة الابداع في العمل الفني • 


\section{أهمية البحث :}

- تكمن أهمية البحث في التأكيد علي دور الثفافية في العملية الابداعية بالثكل النحتي. - - إلقاء الضوء علي أهمية الثفافية كقيمة تشكيلية اثرت فن النحت بالعديد من الاعمال

$$
\text { الابداعية. }
$$

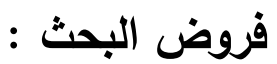

- أن الثفافية كقيمة تشكيلية لها دور فاعل في اثراء مجال الفن بشكل عام و فن النحت بشكل خاص بالعديد من الابداعات الفنية علي مر العصور •

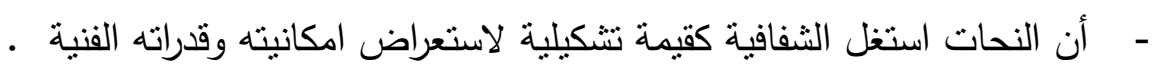
- أن الثفافية تتوعة وتعددة طبقا لمجموعة من المتغيرات مستمدة من الحركات الفنية ل منهجية البحث: - 20 - من - سوف يتبع هذا البحث المنهج الوصفي التحليلي حدود البحث : - - فن النحت والاعمال ثلاثية الابعاد

\section{مفهوم و أبعاد الشفافية}

أعتبرت الثفافية من أهم القيم التي استخدمت كأحد الخصائص المميزة للعمل الفني بشكل غاية في الاحكام من قبل الفنانين في جميع المجالات الفن باشكال مختلفة حيث كان الفنان يبحث دائما عن الاساليب التي تظهر افكاره وتظهر كفائته في ممارسة فنه، ويعد وجود الثفافية في بعض الفنون أمر شائع ومعروف مثل فن الرسم والتصوير والنسيج والفنون البدائية وفنون الاطفال و الفن الحديث خصوصا بعد التقدم التكنولوجي والعلمي. وعرفت الثفافية كمصطلح علي أنها ( هو عدم حجب الروئية و قابليّة الجسم لإظهار ما وراءه )، فاشفافية بما تعنية من وضوح الروئية أضافت إلي العمل الفني بعض الرويي المميزة 
، حيث يظهر العمل ماخلفة للمشاهد، سواء كان هذا الظهور حقيقي أوايهامي أو تعبيري، فهو يمثل اضافة لقيمة تشكيلية دلت علي مضمون فكر الفنان، سواء كان (فكر موضوعي أم روحي أم صوفي أم كوني)، وأسلوبه في التتفيذ مع روحية المادة أو الخامة ، كل ذلك انصهر في بودقه واحدة بتفاعل دينامي يحقق العملية الابداعية، فلا ابداع دون ما هو فكري، ولا ابداع دون روية ناشطة في استتطاق الخامات ولا ابداع ألا بتباع قيم تتكيلية لينتج عنها العمل الفني الذي يحمل بصمة النحات الخاصة. وهكذا وجب تتاول الثـفافية كقيمة تشكيلة يسعيا لادراك الاستدامة في اثراء مجـال

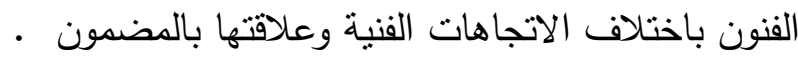

\section{مضامين فكرة الشفافية وعلاقتها بالشكل}

يتراءى لنا من خلال طرحنا السابق لـفهوم الثفافية إن فن النحت كنظام شكلي يحتوي علي عملية فكرية لها مضامين تحكمت في جودة العمل الفني، والمضمون هو الرسالة التي يحملها العمل الفني ، قد تتوعت المضامين بفعل نتوع الثقافات والحضـارات، وقد يرتقي الفكر احيانا ليعلن من علياءه وفق نظمه وعلاقاته الثنكلية المتتوعة بتتوع معطياته واتجاهاته المختلفـة عن وجود الإبـداع ، الذي تطلب مـن النحسات اظهار قدراته ومهاراته ، وتنقى

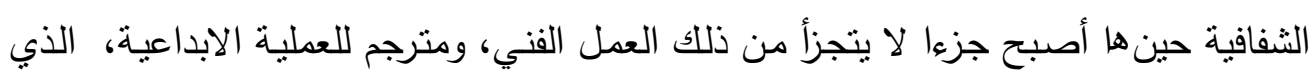
ساهم في تتوع الصيغ التي تتاول بها النحات اظهار الثفافية حتي نحصل علي ابداع فني يحقيق الفكره المرجوه.

\section{- - - مبقا لروئة الفنية قديما}

حدد النقاد الروئة الفنية لدي الفنان الكلاسيكي بمعيار محاكات الطبيعة وتجسيدها وهذا الاتجاه قديم حيث بدأ الانسان في محاكاة الطبيعة ورسم حيواناتها والاحداث الني بها، ونقل أجمل مافيها ، فالصلة بين الفنان والطبيعة لا تتقطع ولكن مايتغير هي روية الفنان، 
وكيف يعبر عنها، "فالنحت الذي عرفناه مع مايكل أنجلو ، ودوناتللو ،كان يخوض التعبير مع الاهتمام بالواقعية البصرية، وكانت موضوعات التماثيل والرليف نرتبط إلي حد كبير بمثالية

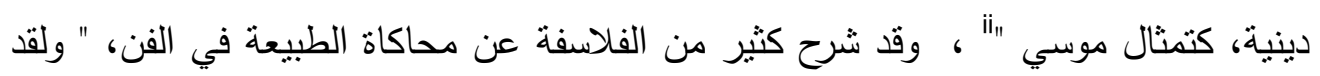
كان (روسو) هو أول من دعي إلي تقديس الطبيعة وتمجيدها حيث تصور أن الطبيعة تقدم للانسان أجمل وأكمل الخطوط ، وكذلك يري (رسكن)أن الفن الكامل الحقبقي هو الذي يعكس

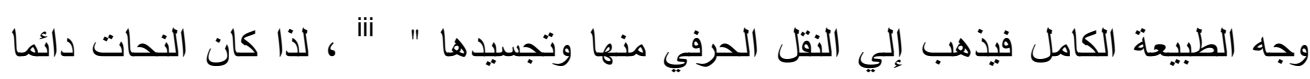
يبحث عن المثل الجمالي في كل شئ في رقة وجمال المرأة أو في جسم الرياضي حيث يتطلب النحت البحث عن مايظهر قدرة ومهارة النحات في التجسيد وامتلاكه لادواته وتمكنه من التقنية وخصوصا مع ماكان يستخدمة من خامات معتمة مثل الحجر والخشب والبرنز وجميعها تحتاج قدرة فائقة علي التصور ومهارة عالية في التجسيد حتي يصل بنلك الخامات إلي الإيحاء بنوع من أنواع الثفافية التي يتمكن النحات من تجسيدها في العمل، الثكل رقم (1) ينحت في صخرة جامدة ليوحي لنا أننا نرى قماشا شفافا فضفاضا حتي يصل إلينا إحساس بنعومة الملمس ورقة الأثنياء وطبيعتها من أسفل ذلك القماش الرقيق ، فهذه ينطلب عبقرية في أداء النحات، حتي يتمكن من إيهام المشاهد بتلك الحالة الفنية التي أدت إلي تجسيد وتصوير الثشفافية في خامة معتمة لكن القيمة النتكيليه هنا نتبع من قدرة النحات علي الاداء المتقن ، أي انها مضامين مستقاة من الطبيعة بتعدد مصادرها الثكلية .

\section{r - طبقا لروئية القنية في الحداثة}

وتغيرت النظرة مع ظهور الحركات الفنية الحديث ، "تحكي الكتب والمعاجم عن

حركات الفن الحديثة في القرن العشرين وتخوض في تفاصيل هذه المدارس وتتأمل أعمال الفنانين وتحصل علي تصريحات منهم فيما يعملونه وكيف تأتي إليهم الافكار ، أن أهم شئ يوصف به هذا العصر أنه عصر علمي فقد وضح التأكيد البارز علي البحث العلمي والتجريب ونظريات العلم ومستحدثاته "iv ، واعتمد فن النحت علي صفة الثفافية الحقيقية 
للخامة متأثر بالتكعيبية التي ظهرت في بداية القرن، وكانت بمثابة ثورة فكرية كبيرة تبعها تحول كبير في فكر كثير من الفنانين فمع بداية القرن العشرين كان الاتجاه الرئيسي نحو البحث عما هو غير مدرك بالحواس ، أو الكثف عن الغير مرئي و البعد الرابع أو الزمن و هن

اكتثاف الاشعة السينية ، وكانت له بصمه واضحة علي ظاهر العمل الفني ومضمونه . واتجه النحات من مجرد الاهتمام بالقيم التتكيلية الظاهرية في سطح العمل الفني، وما به من ملامس وظلال إلي أعماق العمل الفني، والقيم التنكيلية النابعة من داخل العمل الفني حيث انعكاس الضوء وانكسراته ومايشعة من ضوء في نفس الوقت. أب انها مضامين مستقاه من الفن ذاته اعتمادا علي قواعد العلم و مكتشفات العصر •

\section{r- طبقا لروئية الفنية في ما بعد الحداثة}

حاول فنانو مابعد الحداثة اختصار المسافة بين الفن والحياة عن طريق تحرير الفنان من الوسائل والتوجه المباشر لاكتشاف نفسه والعالم واعتماد العمل المباشر بالمادة حيث اراد الفنان التعبير عن ادراك جديد للعالم وعن مفهوم جديد للفن"v، لقد رافقت مابعد الحداثة الكثير من المتغيرات ومن أهمها هو التغير في المعايير الجمالية المتوارثة في الفن التشكيلي فلم تعد المعايير تسير وفق معيار ثابت محدد ومعد من قبل النقاد كمقياس وحيد للفنون، فتعددت المعايير الجمالية التي أصبحت نستقى مبادئها من الفن ذاته، فأصبحت هناك معاييرعلمية- اجتماعية- تاريخية- حضارية-أخلاقية إلى جانب المعايير الأبعاد التتكيلي مبي مبيلية

$$
\text { والفني. }
$$

وظهرت الثفافية في الاعمال ذات الابعاد الثلاثية والتي أستخدمت الخامات التي لاتحجب ما ورائها ويمكن مشاهدتها بالعين وتستخدم الخامات التشكيلية الثفافة متل الزجاج ،البلاستلك الثفاف والاكرلك ، والماء والتلج .......وغيرها ، "نشر البنائيون عام • ب9 ام علي يد (فلاديمير تاتلين) Vladimir tatlin) انهم يرمون الي تحقيق ماهو زماني ومكاني لتمثيل الحياة الحقيقية، ونـادوا بأن الثفافية والعمق يجب أن يحتلا مكانهما في العمل الفني ما دام 
الفراغ يكون بطبيعتة المطلقة عمقا لا ينفذ إليه (لانهائي)وقد استخدموا في الخامات الثفافة vi" كغاية للوصول إلي قيمة المكان بمعني أن تجعله مرئيا بطريقة جديدة تماما " كما تغير مفهوم العملية الإبداعية نفسها، فأصبحت مثل الفلسفة يحدوها الجدل ووضع التساؤلات، وأصبح الفنان مثل الفيلسوف بطرح القضايا حول طبيعة الفن" "vii، وعلية ظهرت العديد من أثكال الثفافية التي لم تكن موجوده سابقا تستمد مضمونها من العلم و الفن لنظهرلنا كقيمة تشكيلية جديدة ، "كما بري الفنان ناعوم جابو أن الفن والعلم هما تياران مختلفان يرتفعان من نفس القوة الإبداعية ويتدفقان إلى نفس المحيط من الثقافة المشتركة، حتي وأن كان لهم أصول مختلفة"viii ، أي مضامين مستوحاة من مصادر اكثر تتوع وتعدد مثل التكنولوجيا والعلم والحياة.

\section{أنواع الثفافية كقيمة تشكيلية وأهميتها :}

ولأجل الإفصاح عن نركيبة العلاقة بين الثفافية والنحت فلابد من رصد نقطة

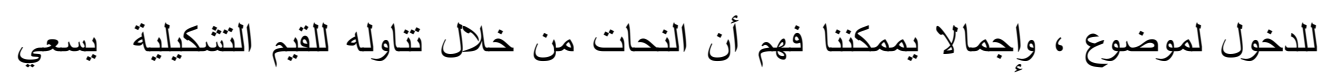
الى السموه الفني والتنظيم الثكلي والجمالي، والثفافية بدورها تعد متغيرا مهما في العملية التشكيلية، يعتبر القول المحد أن الثفافية تكمن أهميتها في قدرتها علي توصيل المضامين الفكرية للنحات إلي جانب المظهر الجمالي كقيمة نتكيلية الذي يخطف نظر الشاهد ويدعوه لتأمل العمل الفني ولاكتشافه وفهمه . ل. ولان فن النحت يأخذ اتجاهات متعددة شأنه شأن ميادين الفن الاخرى بتتوع طبيعة الاتجاه الفني، لذلك فهو دائم البحث عن تحقيق القيم التتكيلية في العمل الفني، ولهذا يمكن تقسيم الثفافية إلي عدة مداخل طبقا لما تحمله من مضامين فكرية وهي كلاتي : 1. شفافية تتحقق من خلال التجسيد مظهر الثفافية r. الثفافية الحقيقية من خلال الخامات الثفافة بطبيعتها 


\section{r. شفافية تتحق من خلال التشكيل بنسج المفرغ في الخامات المعتمة ع. الثفافية التعبيرية في الخامات المعتمة ه. الثفافية الايهامية عن طريق الخداع البصري 7. شفافية تحقيق عن طرق الحركة الفعلية V. شفافية تتحقق من خلال الضوء والنحت الرقمي}

\section{ا - شفافية تتحقق من خلال التجسيد مظهر الثفافية}

هي ناتجة عن القدرة التصورية للنحات وهي ترطبت بشكل وثيق الصلة بأداء النحات وتمكنه من أدواته وتقنياته ،.أي أنها شفافية تجسيدية لاتتتج عن أستخدام خامة بطبيعتها شفافة ، ولكنها لتجعل المشاهد يقدر قيمة الجمال الكامن وراء تلك الثفافية، ندها في الطبيعة من مظاهر يدركها النحات، وينقلها من خلال عمله الفني . بالرجوع الى منجزات الفن التشكيلي في العصر الكلاسيكي فعدها نشاهد شكل (1)، تمثال فينوس جينيتركس (الأم) Venus Genetrix للفنان كاليماخوس العصر الكلاسيكى المنفذ بأسلوب النحت المباشر على الرخام، "نتأكد من أنه لو كان قد صنع من خامة أخرى غير الرخام لتحول إلى تمثال آخر ولأفتقد قدرة التعبير عن معنى الرقة ، والجمال الناعم والعزوبة ، والتى هى من الطبيعة الثكلية الخاصة بخامة حجر الرخام وملمسه ذاته و "من خلال محاولة تحقيق المثل الجمالي الأعلى، وتمثيل الجسد البشري في نسبه الذهبية المثالية ، مضافا الىها قدرة التعبير، تبدو البراعة التقنية للنحات وعبقرية أداءه فى نحت الرخام، وتفهمه لإمكانياتها النشكيلية مستفيدا من خصائصه الحسية فى محاكاة جسد المرآة بكل دقة وحساسية ووضوح للتفاصيل وإبراز ثثايا الثياب التى ترتديه والثفافية التى تبرز مفاتن جسدها ، فكان العمل منضمنا لمعنى الرقة والجمال فى الجسم الأنثوى الناعم العذب والأناقة والجالال فضلا عن تجسيده الثفافية التي حققة قيمة الجمال الذي استطاع فيه الفنان ايضا 
أن يوفق بين عناصره التتكيلية من حيث عمليات التظظيم والترتيب، والتجسيد، حتي تمكن من تحقيق الثفافية بكل هذه الدقة في الاداء ، وهذا العمل خالد ليس لأهميته التاريخية فحسب، وإنما لأنه تعبيراً صادقاً يحمل قيماً تشكيلة رائعة." فئ. نشاهد في شكل رقم (Y r r) تمثال الحقبقة المحجبة وتوجيا للنحات الايطالي

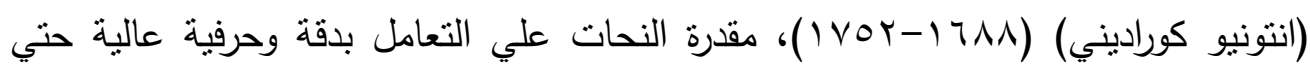
تمكن من اظهار جمال الوجة من تحت هذا الخمارالثفاف الذي يغطي الرأس والوجهة والمشاهد يجد نفسة في تمام الاقتتاع بأن الوجه يظهر من خلال طبقة رقيقة وشفافه من القماش و يظهر جمال ملامح الوجة والعيون النائمة من أسفله وساعد ذللك في اظهار وتجسيد الثفافية كما يشاهدها الفنان في الطبيعة تماما دون أي تغيير عن ماهو كائن في الطبيعة ويؤكد ذللك الثكل رقم (0،؛، ؟) تمثال المسيح من خلال الوشاح للنحات الايطالي

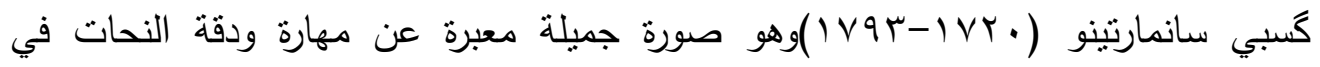
الوصول إلي اقصي درجات الدقة في استغلال القدرة العالية علي التشكيل واظهار الثفافية كقيمة جمالية وشكلية فالنحات يجسد صورة انسان يظهر عليه عناء وتعب والم من تحت ذلك الوشاح الرقيق الذي يغطي كامل الجسد ويظهر الملامح والتفاصيل في عامة الجسم بتلك الضلوع المتراصة للقص الصدري والعضلات المرهقة النحيله والتي استسلمت للموت ونسنطيع تميز الوجه الذي يرسم عليه العناء والتعب من شدة الالم كما يمككنا مشاهدة اكليل الثوك ومسامير الصلب بجوار الجسد ملقاة علي الفراش تأكيد علي المعاناه فنجح الفنان للوصول من خلال الثفافية لتحقيق مضمون المعاناه الالم . "وهذا النوع من أنواع النحت الذي يظهر فيه اقصي مهارة من النحات على التصور، وقدرة عالية علي التجسيد لاتضاهيها مختلف القابليات والمهارات، التي تستلزمها بقية الفنون الاخري ،كانت وماتزالت من أهم وافخم منجزات النحت عبر التاريخ، هي تلك الاعمال التي انجزها 
العدد الثاني عشر / المجلد الثناني المجلة العلمية بحوث في العلوم و الفنون النو عيه

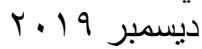

شيوخ النحاتين واوحت لنا بروئة الشخوص وقد غطاهم وشاحا شفافا نستطيع ان نرى من خلاله كامل ملامحهم دون اي غموض، هي اعمال خالدة حيث تعد مثال واضح علي الثفافية التجسيدية التي يصور فيها الفنان جماليات الطعبية "x.

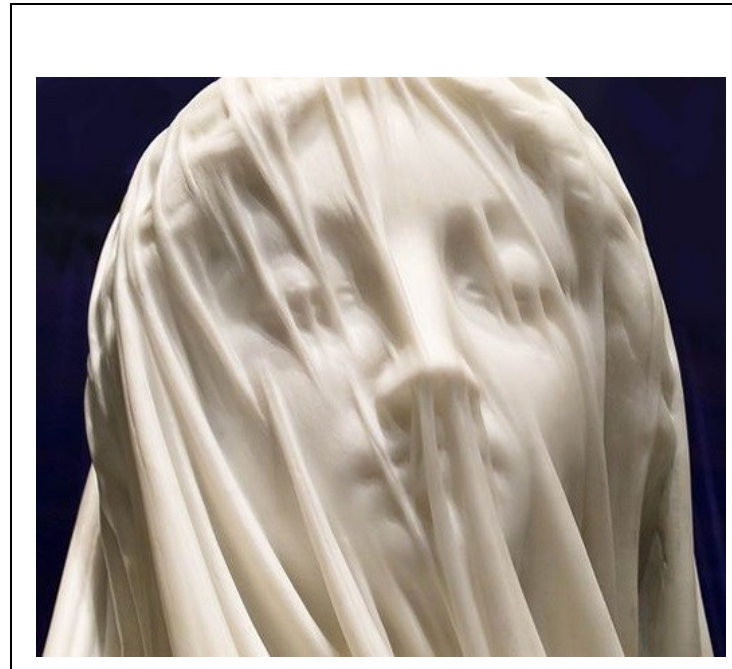

(r) شكل

الحقيقة المحجبة وتوجيا للنحات الايطالي انتونيو كوراديني (I )

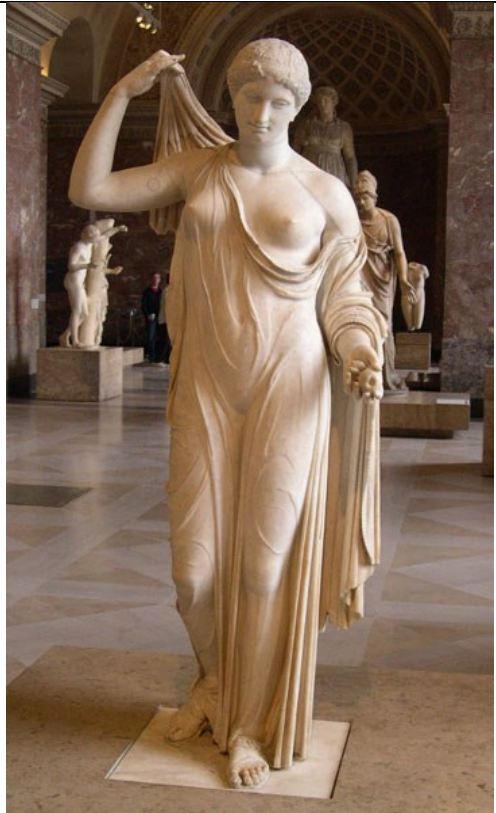

شكل (1)

فينوس جينيتركس (الأم) "كاليماخوس" العصر

$$
\text { الكلاسيكي }
$$

نحت مباشر علي الرخام. متحف اللوفر 
العدد الثاني عشر / المجلد الثناني

المجلة العلمية بحوث في العلوم و الفنون النوعيه

ديسمبر 9 1.

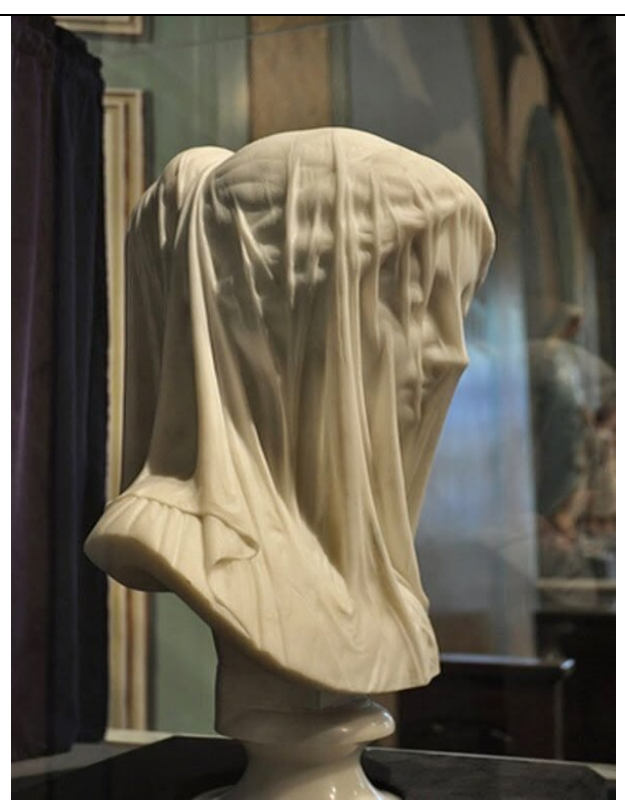

شكل (r)

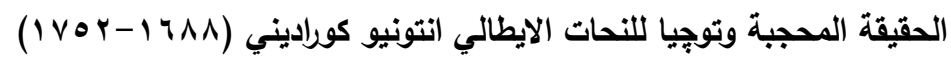

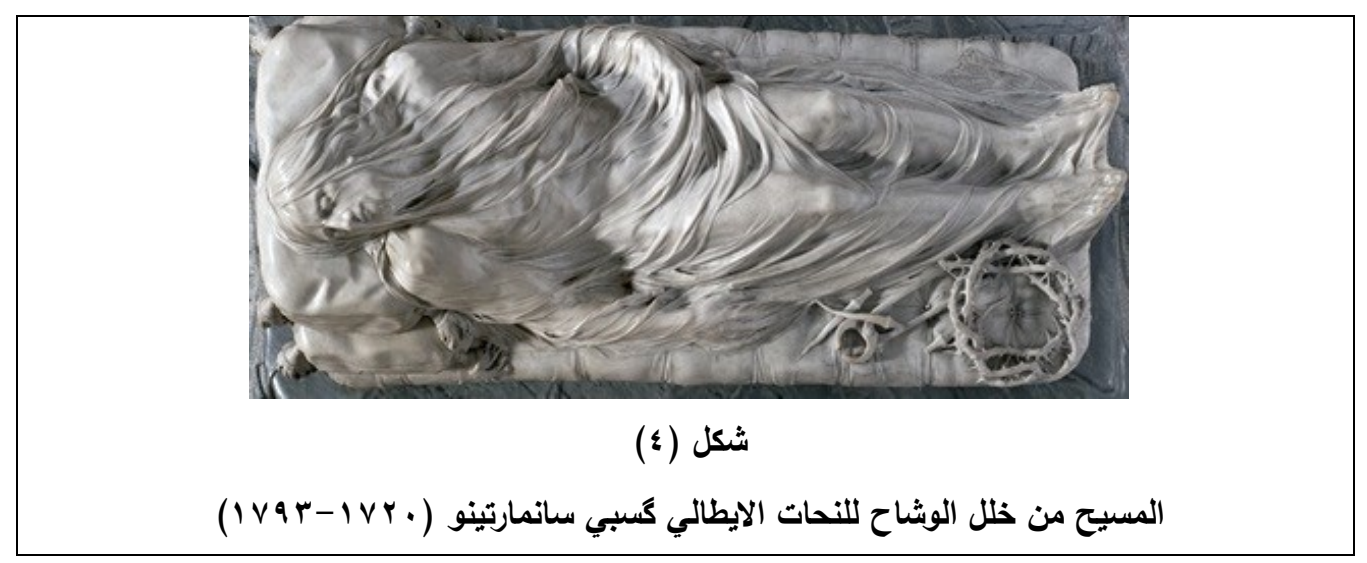

$\Lambda$. 


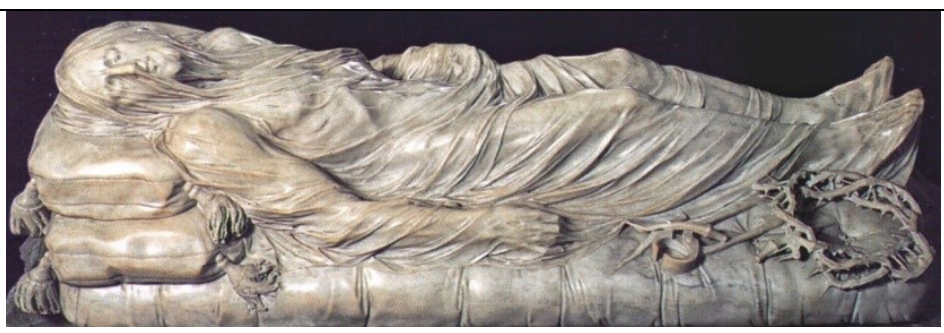

(0) شكل

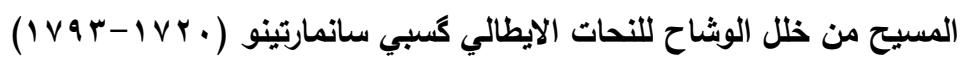

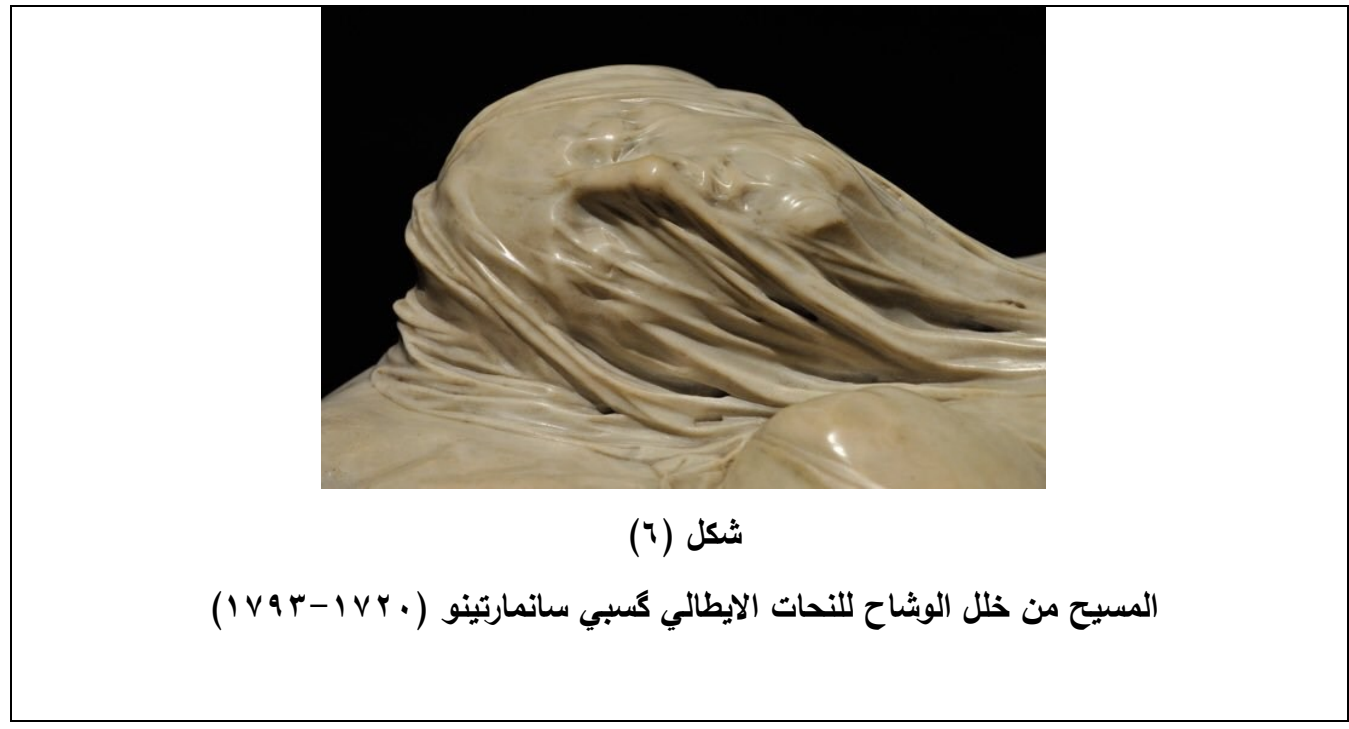

\section{r- الشفافية الحقيقية من خلال الخامات الشفافة بطبيعتها}

الثفافية الناتجة عن الوسائط الفيزيائية الحقيقية التي تتمتع بخاصية الثفافية تستخدم الخامات التي لا تحجب ما ورائها، أي أنها شفافية حقيقية لايوجد بها أي استخدام لايهام أوالحيل وهي تلك الثفافية بمعناها الحرفي الذي نجده في الطبيعة من خواص بعض 
المواد التي تسمح بمرور الضوء، أو الصورة من خلالها او تلك التي قد تمرر بعض الضوء فتغير من قيمتها ووضوحها .

واستخدمت الخامـات الثـفافة والنصف شفافة في بنـاء الاعمال الفنيـة للحصـول علي العمق المتصل والمستمر بمعني أن يكون الثكل مرئيا بطريقة جديدة بتحطيم الحواجز المرئية

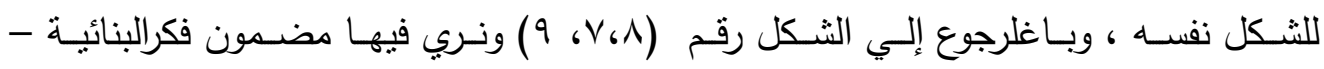
الاعمال للنحات ناعوم جابو ذلك المهندس الذي استخدام المواد الثفافة و العناصر الإنثائية ذات التأثير الفضائي حي.ث صنع لنفسه مزيج خاص به لبناء العمل الفني ، " ومـع استعرض نمـاذج جابو بشكل عام تظهر لنا قدرته علي استخلال خصـائص المواد الثفافة من خـلال عمليـة الدمج والربط بين المواد بطرق مختلفة مـن أجل إظهار حسالات التفاعل بين الكتلـة

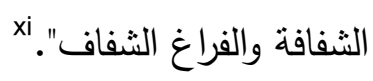

فظهرت أعمالة لتبحث عن كل ماهو جديد ومختلف ، حيث استخدم في بناء عمله خيوط من النايلون الثفاف، الذي ينفذ منه الضوء ليظهر للفن نماذج غير مسبوقة من منحوتـات لها صبغة هندسية تجريديـة غايـة في الدقـة والجمال، خرج بها مـن حيز الكتلـة المصمطة إلي حيز الثفافية المجسمة.

" ويتتاول الفنانون المعاصرون خاصية الثفافية بطريقة جذابة ومشوقة فيجعلون من المسطحات الثفافة تتخيما بضفي علي أعمالهم نوعا من الحيوية والرقة والرشاقة، كما أن الوحدات التي تتراكب بواسطة هذه المسطحات الثفافة تؤدي دورا في تحقيق وحدة العمل الفني

$$
\text { xii " وترابطه }
$$

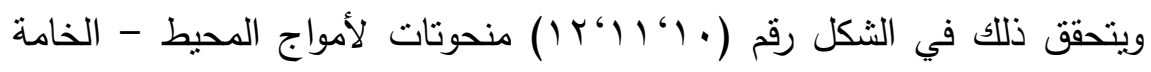
شرائح الزجاج - الفنان (بن يونغ)، وهي منحوتات "تعبر عن أمواج المحبط، والمناظر 
الطبيعية المائية نفذت بخامات شفافه بطبيعتها من خلال طبقات متعددة من شرائح الزجاج الرقيقة، حيث يستوحي الفنان أعماله من حب الفنان للمحيطات من ركوب الأمواج والماء الازرق، " لذلك اختار هذة الخامة لما تحمله من نفس حصائص الماء من حيث الثفافية وظهار المحتوي الكامن بداخلها وهنا يكون الفنان قد مثل جمال الطبيعة بشكل واقعي لكنه xiii بنهج المدرسة البنائية

ونلاحظ نوع اخر من المدرسة البنائية ، الثكل رقم (rا"؛ () "لروبرت ميكيلسن

أسم العمل الدانتيل الزجاجي وهو أسلوب انيق في التشكيل وبناء العمل يختلف عن الاساليب السابقة ناتج عن قدرة الفنان في التصميم والتجسيد النحتي بشكل ابداعي عن طريق تشكيل xiv"الزجاج باسلوب مبتكر ليعطي ايحاء بالدنتيل الذي يعبر عن الرقة والجمال

وفي نطاق الفن تتعدد الاتجاهات حسب تناول الفنان للموضوع فنلاحظ مدي الاختلاف لتتاول نفس الخامة لكن باسلوب يطغي علية الفكر الميتافيزقي قي الثكل رقم (0) تمثال لامرأة في وضع 》ماعته، للتشكيلية المصرية حورية السيد: وتعني العدالة عند المصري القديم، ولكن ببورتريه معاصر وبشعر حر ، وجسد شفاف مضيء برمز إلى النورانية،

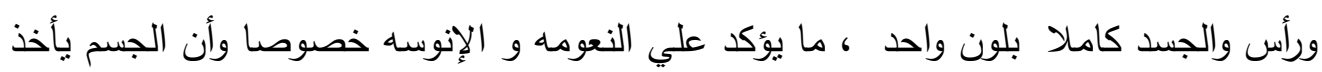
شكل مموج ناعم ، وهو من الاعمال التي تتنمي الي الميتافيزيقيا المصرية، التي تعبر عن القوى الكامنة وراء الطبيعة ، محاولة إيجاد أبعاد تثكيلية لها معايير خاصة بالنحات، واستخدامت الزجاج لانه خامة قريبة بطيعتها الثفافة إلي النورانية التي ترغب في التأكيد عليها ، وقد جاء علي لسان النحاتة "أن لكل خامة صفات يجب أن تعرفها وتحترمها قبل التعامل معها فالزجاج خامة النورانية، ولكنها لا تقبل الخطأ. تعامل مع الكتلها المصمطة باعتبارها تستمد قوتها من الثفاية الكامنه فيها كخامة تتشكيله والتحدي الصعب الذي يواجه 

العدد الثاني عشر / المجلد الثناني
المجلة العلمية بحوث في العلوم و الفنون النوعيه

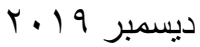

النحات كيفية صياغة الفراغ المتتاغم مع الكتلة النحنية، وأن نكون العلاقة بينهما منزنة، فت xV" فتعايث الكتلة الثفافة مع الفراغ الثفاف
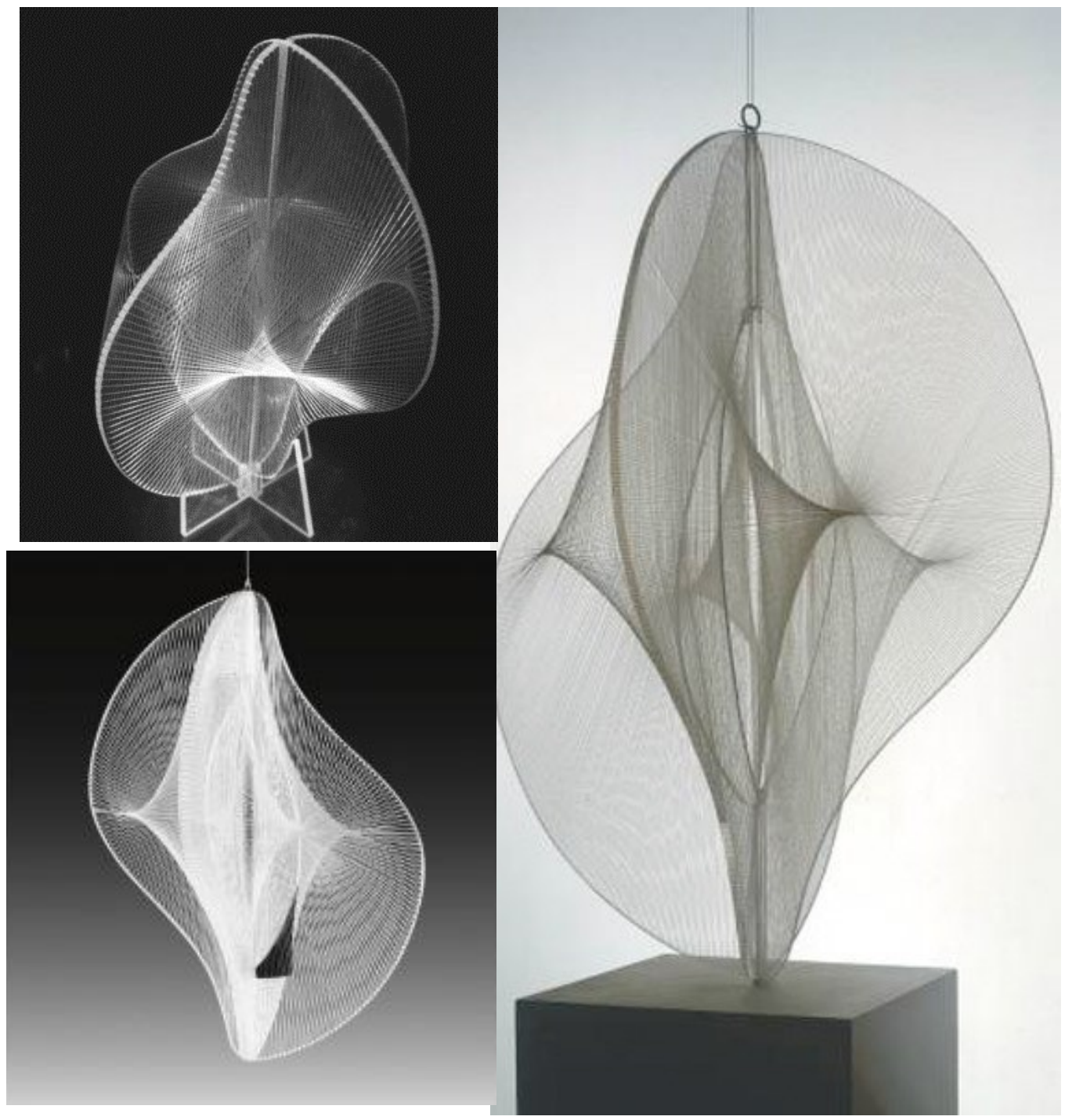

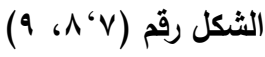


من أعمال البنائية للنحات ناعوم جابو - الخامة الخيوط النايلون الشفافة

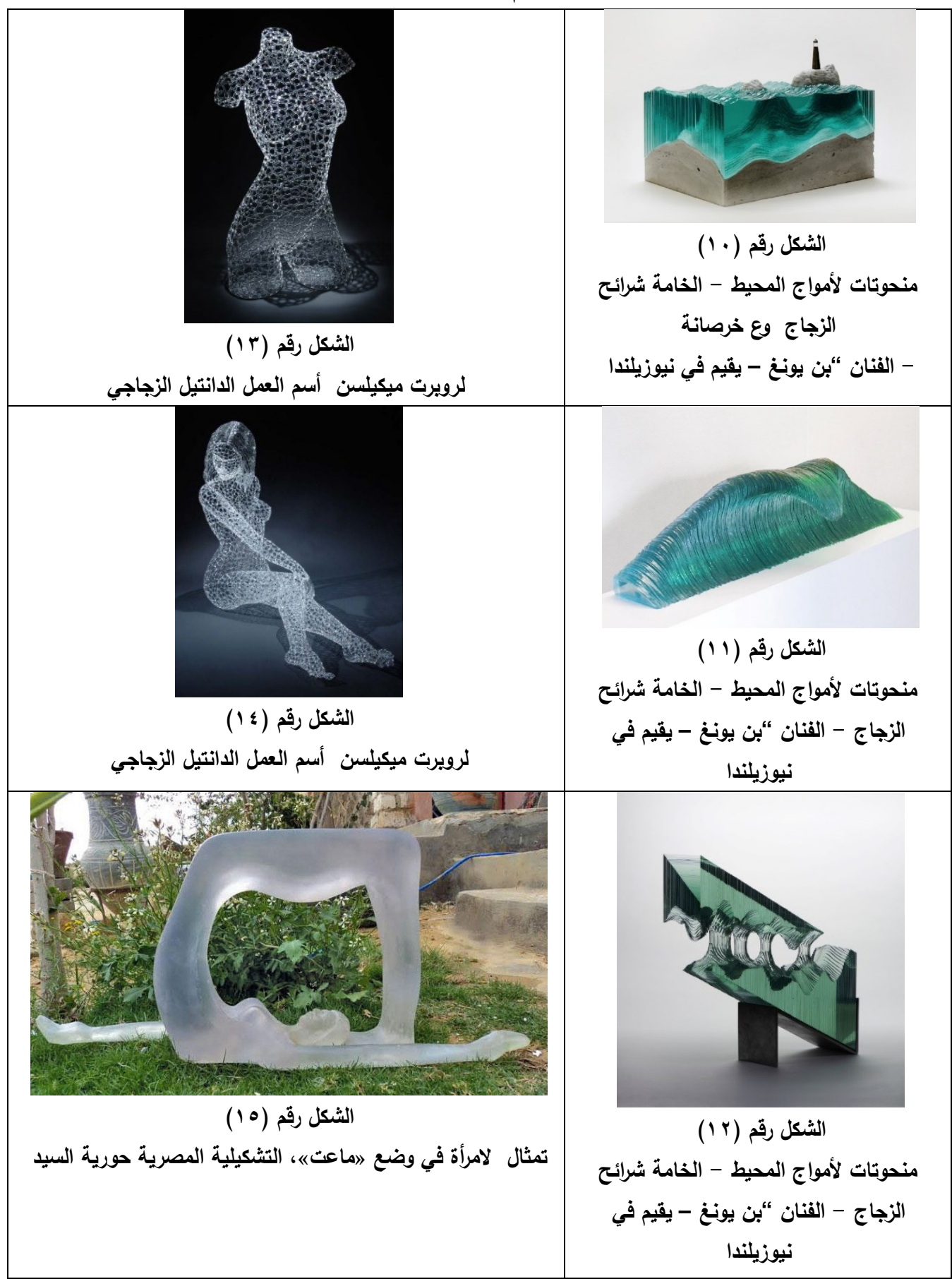




\section{r- شفافية تتحق من خلال التشكيل بنسج المفرغ في الخامات المعتمة}

نلاحظ أن لكل خامة معطيات خاصة من حيث أن هذه الخامات بها سمات شكلية

تتصل بعناصر العمل الفني المختلفة لذا وجب علي الفنان استخدام مهارته الفنية في نكيف الخامة لتحقيق الثفافية حتي وأن كانت الخامة معتمة .

ولان " ومهارة الفنان تكون خاضعة للعمل الفني وقيمتها في كونها وسيله بطوعها

الفنان حسب متطلبات عمله، وتحت إرادته واتجاه الخامة ، أي أن وظبفة المهارة هنا هي إخراج العمل الفني وإحكام السيطرة علي ما فيه من صنعة ، ولهذا فهي خاضعة لمقتضيات الخلق والابتكار فتسمد وجودها وطبيعتها من طبيعة العمل الفني المتصلة به، ومن طبيعة القوي التعبيرية الدافعة "xvin، وهي طاقة هائله تخضع كل شئ لخدمتها، وهذه القوي ليست جامده ، فهي تتغير بتغير الاشخاص لذلك نلاحظ نتوع الاساليب المختلفة في تطويع الخامة

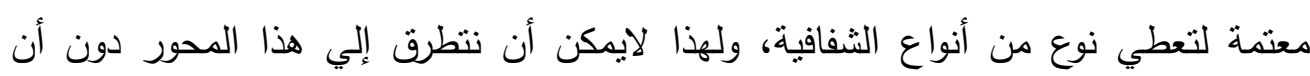

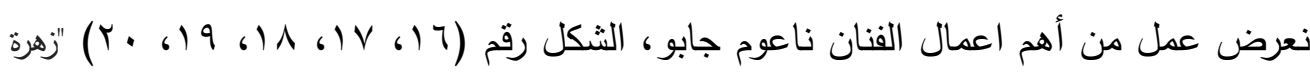
ونحل، نحت المعدني، والموقع، بالقرب من متجر "دي بيجينكورف- بهولاندا ، "لانه منذ بداية الحركة الإنشائية كان واضحا بالنسبة لناعوم جابو أن النحت الذي شيد، من خلال أسلوب المدرسة

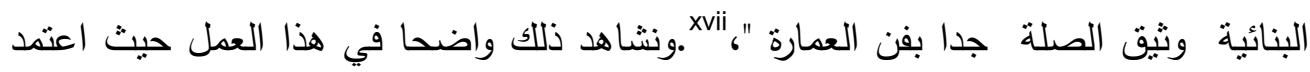
جابوا علي البناء بالاساليب التي من شأنها أن تدمج عنصر النحت مع العنصر المعماري في وحدة واحدة، " فنري استخدم لعملية بناء بطريقته التتسيقية الجميلة و يسطر فيها الخطوط المتتاغمة، الني تبني الثكل بهندية دقيقة لكنه استبدل خيوط النايلون الثفافة، الذي ينفز منها الضوء بأعمدة معدنية من الفولاز بينها فراغات ينفز من خلالها الضوء وبذلك يحقق نوع من الثفافية في الخامة المعتمة التي تعد ضرورة لبناء هذا العمل القيم • 


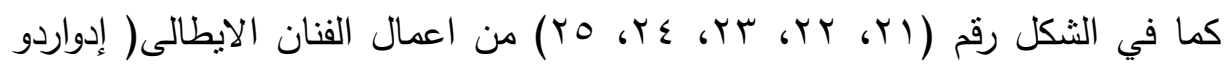
تريزولدي ) قام باستخدم الاسلاك المنسوجة بشكل فنى جميل، و حولها الى تحف فنية وقام بعرضها فى معرض الصور الفنى فى ايطاليا، ونري هنا الفنان وهو يستغل مهارته في التجسيد وتصوير الجسم البشري بشكل واقعي دقيق جدا، في أوضاع الحركة المختلفة التي قام بتتفيذها باستخدام السلك الثبك المنسوج من المعدن استعرض به مهارته في النتكيل، وحقق فكر تفاعل الفراغ مع الكتلة الثفافة .

ويظهر لنا اسلوب أخر من استخدام النسيج كتقنية لتحقيق قيمة الثفافية في العمل الفني ثلاثي الابعاد، في أعمال الفنانه بربارا ليشا النحاتة الاسترالية الثكل رقم ( צY، VY،

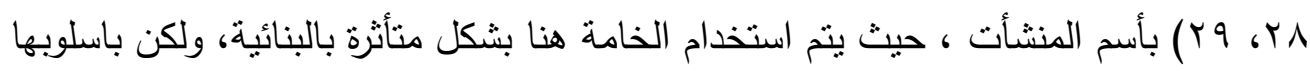
الخاص وهونسج الاسلاك المعدنية، للحصول علي غرف ومكعبات بها فراغات بينية نظهر المحتوي الداخلي، حيث ثبتت في كل غرفة شخص أو اكثر مصنوع ايضا من السلك المنسوج، محدثة نوع من الثفافية يختلف في كونه يعتمد علي الفكر التعبيري ، وقد جاء الي لسان النحاته " لطالما أثثار اهتمامي تعقيد سلوك الناس، و التثنيلات العاطفة التي بينها أوجه شبه ، بين الناس العاديين الذين صادفتهم في الحياة الحقيقية ، والناس الذين يعيشون في خيالي وفكري الداخلي ، فألهمني ذلك اكتشاف اسلوب للتعبير بصرياً، عن مدى المشاعر التي أراها في الحباة الإنسانية"xviil أي انها تلجاء لهذا الاسلوب في استخدام للتعبير عن عمق وتعقد المشاعر الانسانية، وتهدف الفنانه تحقيق العمق المتصل والمستمر، بمعني أن أن التهاء يكون الثكل مرئيا بطريقة جديدة بتحطيم الحواجز المرئية للثكل التقليدي وذلك من خلال وضع المستويات منراكبة، والتي تظهر فيها المساحات والفرغات عبر تشبكات الاسلاك مع بعضها البعض، لتصل الفنانة إلي القدرة علي التعبير المرجو • 
والثكل رقم (•r، آب، rr، Mat Szulik(r) مات سوليك ، مجموعة من أعماله تحت مسمي (اسلاك)، ونري النحات البولندي( مات سوليك ) ، وقد أهتم بأنستخدم الاسلاك الملونة في بناء أعمالة، وينسجها بشكل هندسي شديد الدقة بحيث يحقق فيه قيمة الثفافية، حتي يظهر لنا ما في باطن الهيكل المكون لجسم الحيوان، وقد جاء علي لسان الفنان "انها رؤية أخرى لحيوانات الغابة كما نعرفها مثل الخيول، الخنافس، والنمل والكلاب وغيرها من الحيوانات، باستخدام أسلاك فضية لامعة في الأغلب، مع احتواء عدد منها على أسلاك أخرى ذهبية اللون، كطبقة إضافية تمثل بُعدًا آخر لمنظورنا لهذه الحيوانات، لتجسيد جمال

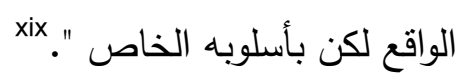

\begin{tabular}{|c|c|}
\hline 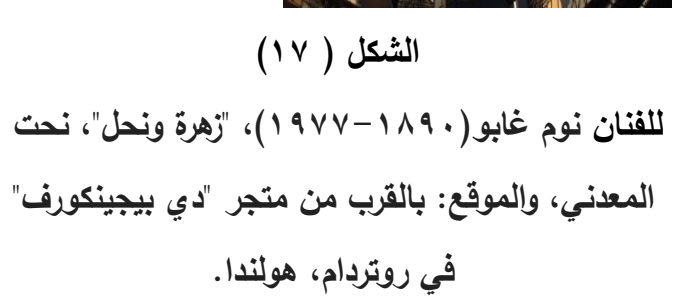 & 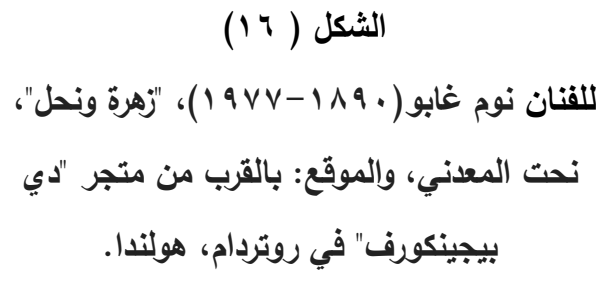 \\
\hline
\end{tabular}


العدد الثاني عشر / المجلد الثناني المجلة العلمية بحوث في العلوم و الفنون النوعيه

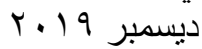

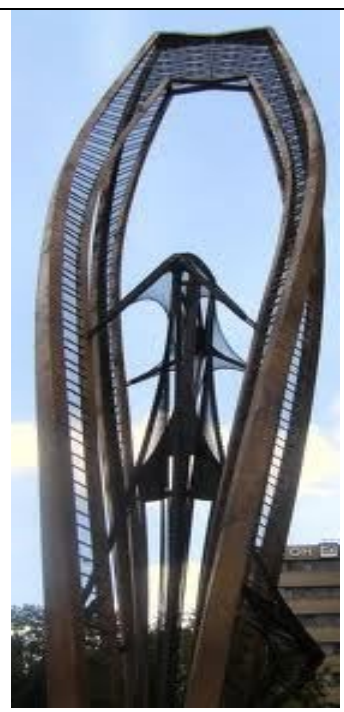

الشكل (

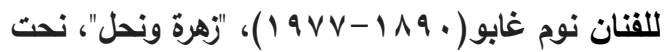
المعدني،والموقع: بالقرب من متجر "دي بيجينكورف" في روتردام، هولتدا.

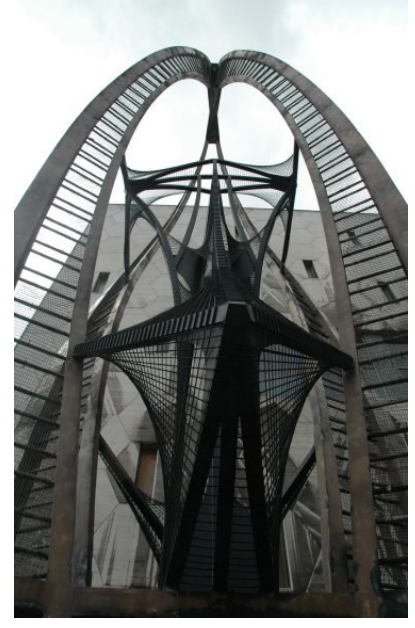

الشكل (1^)

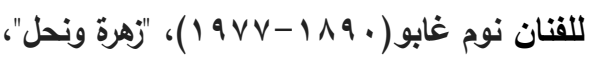

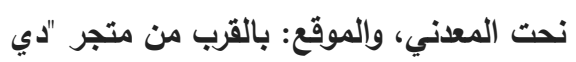
بيجينكورف" في روتردام، هولندا.

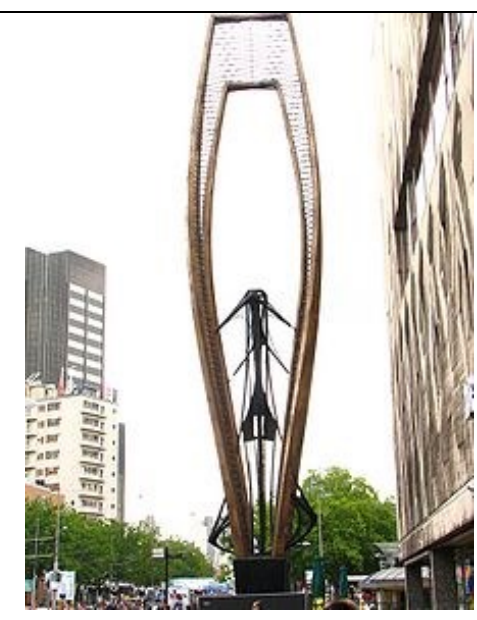

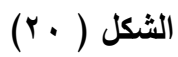

للقنان نوم غابو( • 9 A

والموقع: بالقرب من متجر "دي بيجينكورف" في روتردام، هولندا 
العدد الثاني عشر / المجلد الثناني

المجلة العلمية بحوث في العلوم و الفنون النو عيه

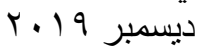
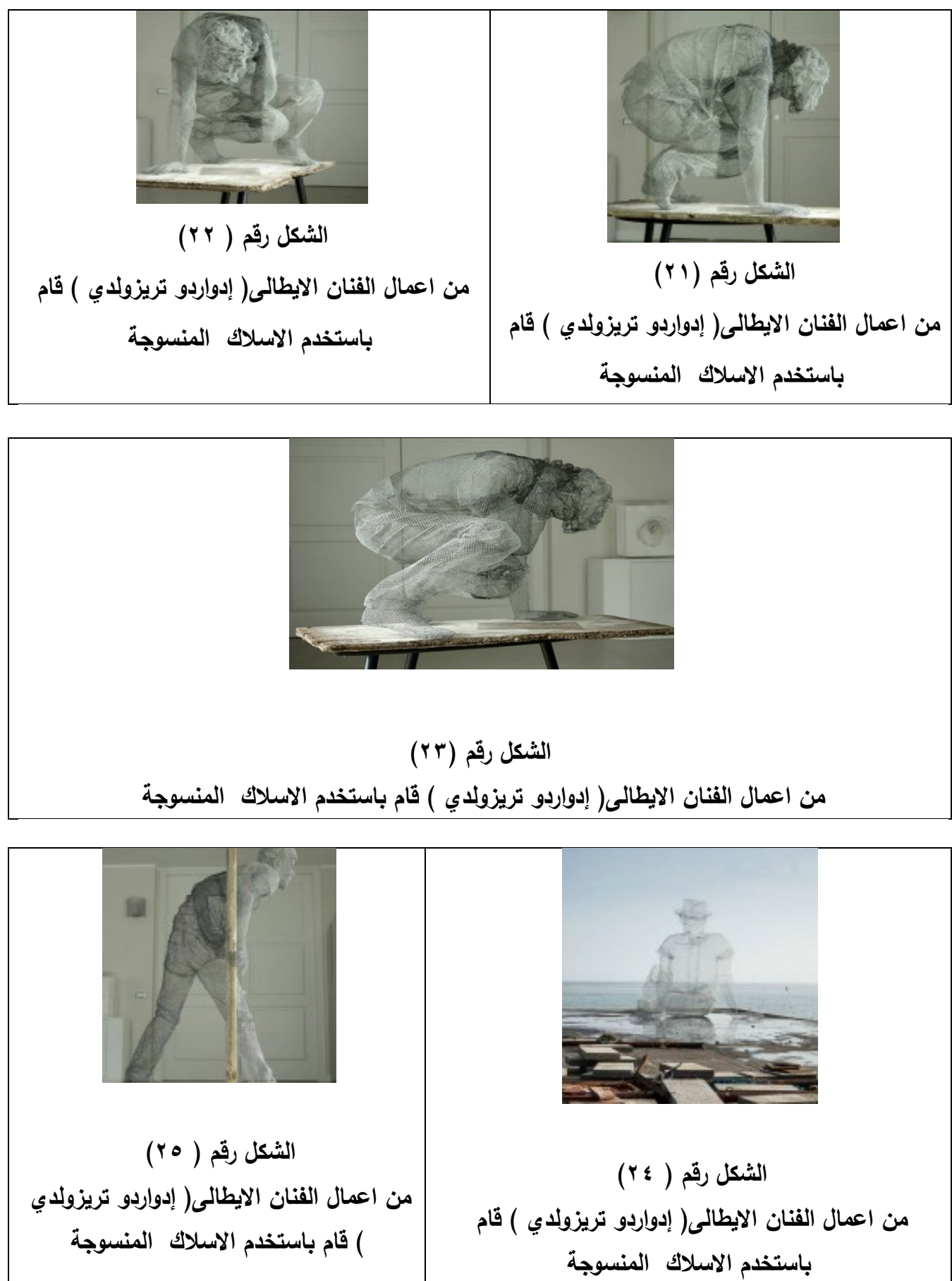

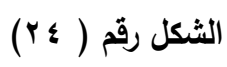

من اعمال الفنان الايطالى( إدواردو تريزولدي ) قام باستخدم الاسلاك المنسوجة 
العدد الثاني عشر / المجلد الثناني المجلة العلمية بحوث في العلوم و الفنون النو عيه

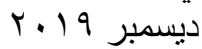

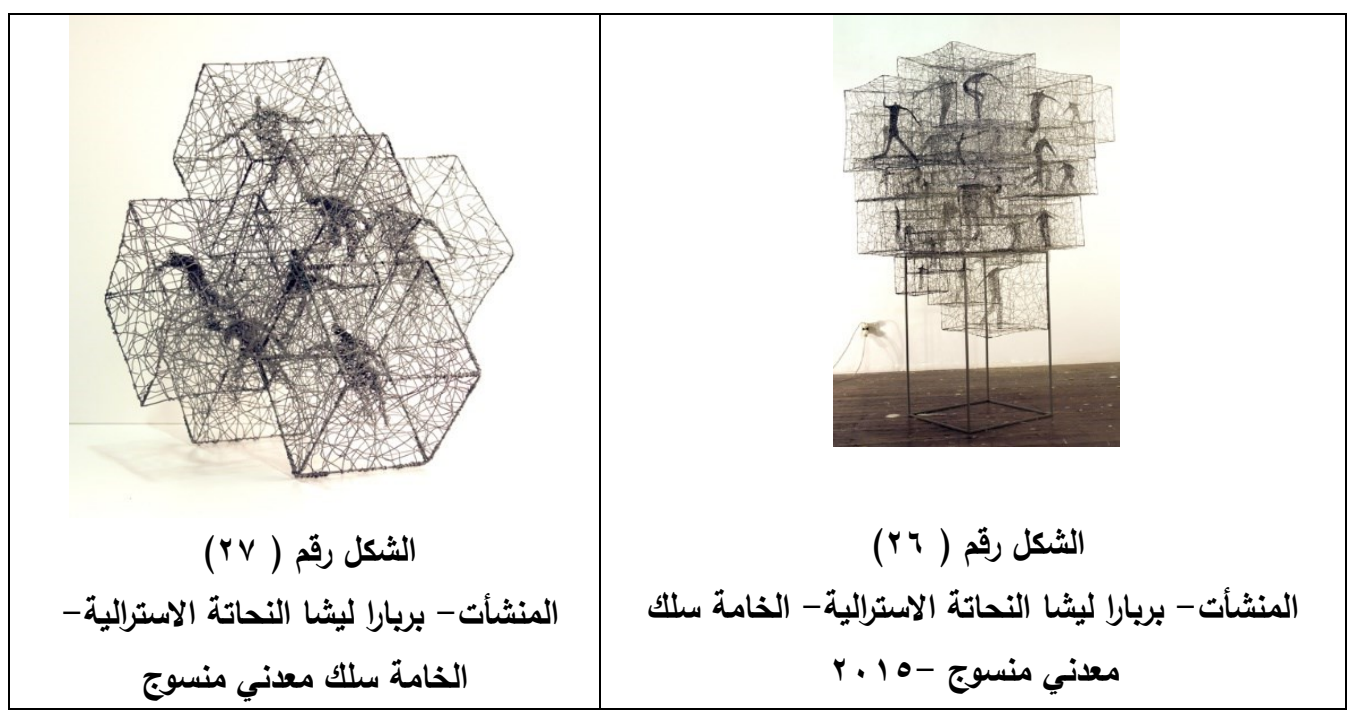

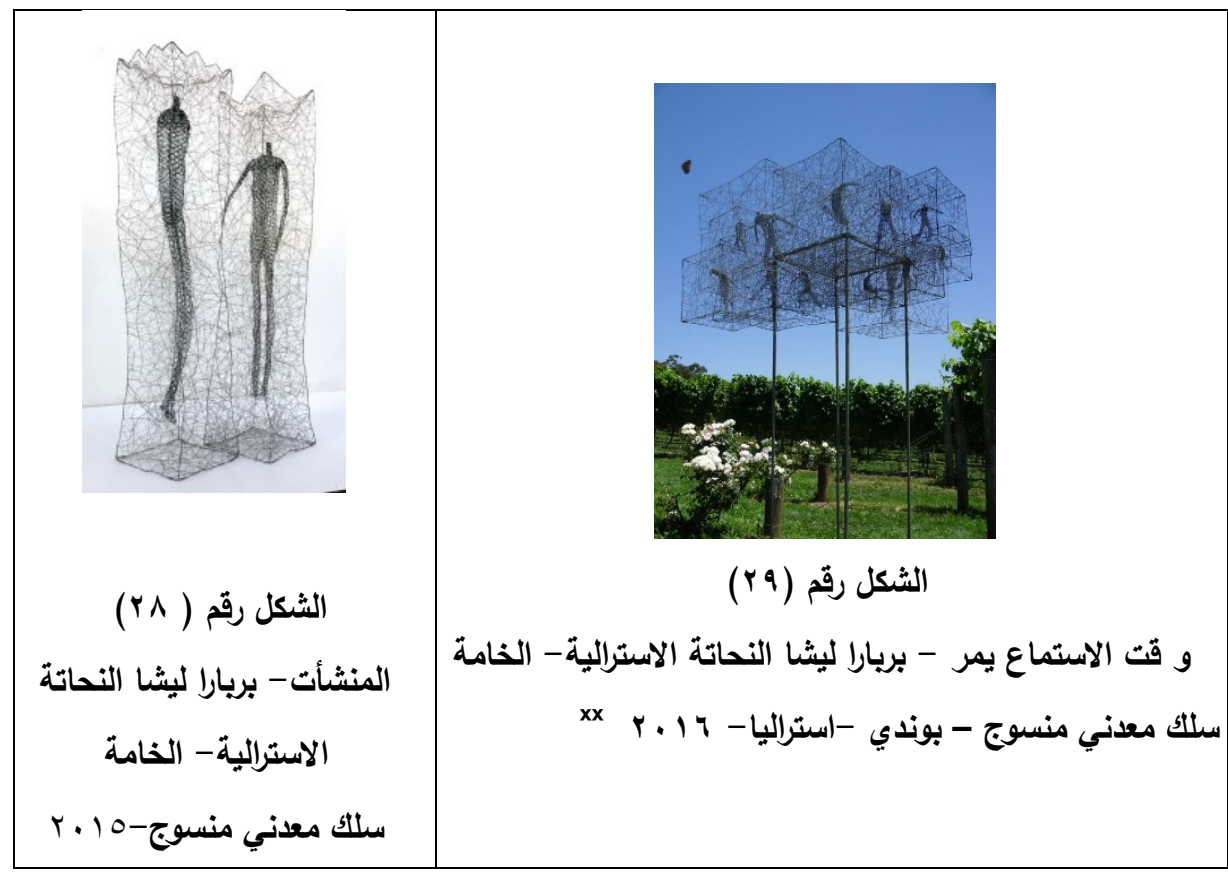


العدد الثاني عشر / المجلد الثناني

المجلة العلمية بحوث في العلوم و الفنون النو عيه

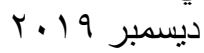
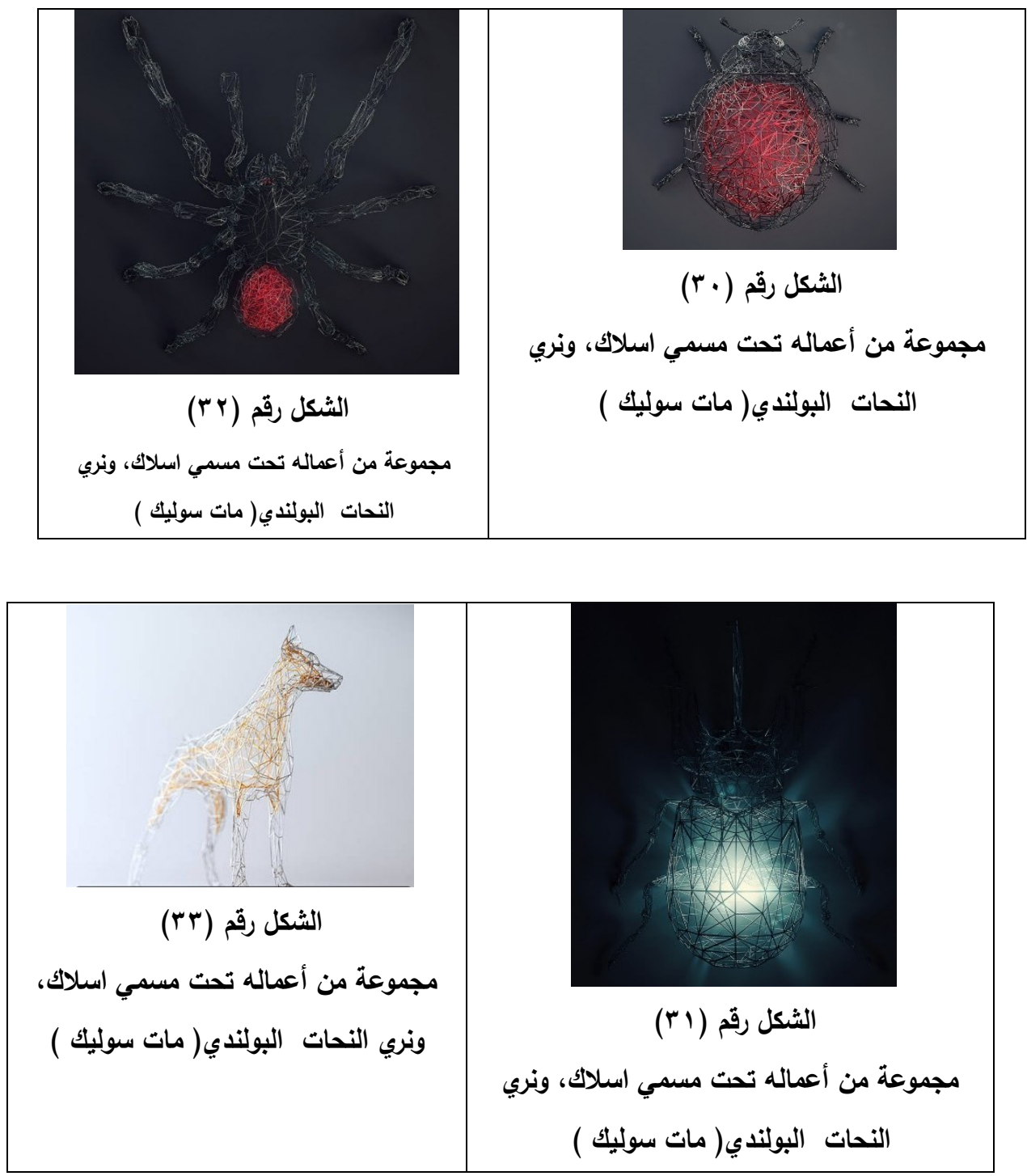


\section{ع- الثفافية التعبيرية في الخامات المعتمة}

تلعب الثفافية في العمل الفني دورا مهما في العملية الإبداعية ، خاصة في الحركات المعاصرة، وأصبح الكثبر من الفنانين يبتكرون أفكارا لتكون بمثابة المثير و محرك طاقي للتعبيرية كامنة ، تلك الطاقة التي تعطي حسا خاصا للخامة، وتخرجها من دورها المعتاد أو شكلها المتعارف عليه إلي والجود من جديد ، وكأنها اكتشفت من خلال روية وإبداع للنحات الذي أعطاها طاقته تعبيرية خاصة

فالنحت وكما هو معروف يشكل قوة تعبيرية، وحين يلجأ النحات لاستخدام الثفافية كفكرة للتعبير عن تصوراته، وانطباعاته التي شكلتها المؤثرات العامة للحياة، من خلال الإنتاج الفني له ،إلا أن هذا الفن يبدأ من تللك المحاولة عن طريق استثارة مكنونات تلك الانطباعات، والأفكار التي وجدت في تركيبه الحسية لاي الفنان، والتي سبق لله إدراكها في ظل تأثير الواقع المحيط به، ثم يحاول التعبير عن تلاك المؤثرات، والأفكار بواسطة استذكار صور محددة للنتكيل الفني وفقا للخامة المستخدمة في التعبير عن مضمون الفكرة، الثفافية وفكرة (الحضور و الغياب)، وينطلق من فلسفة (جاك دريدا )حول مفهوم الحضور و الغياب، وبحسب دريدا فان الذاكرة تتجاوز اللحظة الحاضرة، فيمكن للفنان استحضار منظر ما بدون الوصف الدقيق، لعناصره فالواقع أنة ليس بالضرورة حضور الثئ، و انما غيابه هو الذي يكون الباعث و الحافز لتحريك الابداع.

ومن الملاحظ أن الثفافية تتحقق بحذف جزء من كتلة العمل، والاستغناء عنها ليس بهدف انها ليست مهمه، وانما بهدف خلق نوع من التعبير عن وجود شفافية،بحيث تظهر من خلال كتلة العمل، فتضفي عليها روح الغياب، وانعدام الوجود عن طريق اظهار ما وراء كتلة العمل الفني ،المصمطه ويتضح ذلك في الثكل رقم (عَ، هب، ب؟ب) أسم(منحوتات نلاشي 
في الغربة) ، حيث قام الفنان (برونو كانالانو)الفرنسي من اصل مغربي - . 197 كوهو يشتهر عالميا بالمنحوتات ذات الاجزاء المفقودة، هذه المنحوتات الأصلية ذات ذات الأسلوب الفريد من نوعه، والمنتشرة علي شواطئ مرسيليا ، وموضوع منحوتاته الرئيسي هو السفر والمسافرين، أما ما يميز فنه فهو استعراض سلسلة من التماثيل البرونزية حيث يقوم بنحت جزء مرئي للتمثال، وجزء غير مرئي... تاركاً للمشاهد تخيل الجزء الغير مرئي.

فنرى أن الكتلة والفراغ في المجسمات تلك هي محيرة للمشاهد، وهذا ذكاء من الفنان صحيح أنها منحونات متمانلة ،لكنها توصل مضمون الاغتراب والترحال فالثخصيات لها ملامح تعبيرية لكل واحد من هذه الثخصيات همومه وأوجاعه الخاصة واسبابه للرحيل إما رجل يحمل حقيبة أو قيثارة، أو سيدة بيدها شمسية، أو حقيبة، لربط الجذع مع ساق واحدة واله بأي عنصر كان، والساق الأخرى تكون منفصلة وثابتة على القاعدة، و الفنان استطاع جذب لهن انتباه المشاهد وتصور أناس يبحثون عن أنفسهم وعن أجزائهم الضائعة، .وقد جاء علي لسان النحات "وفقدان التماثيل لأجزاء كبيرة من الجسم جعل المارة في حيرة من أمرهم.. كيف يمكنها الوقوف بهذا الثكل والبعض الآخر استغل وجودها لالتقاط صور مميزة تظهر الييئة

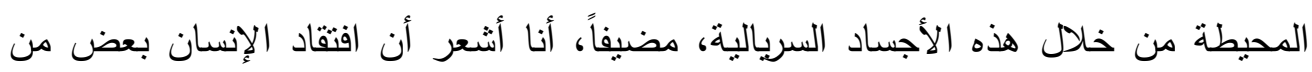
أجزاء جسده يحدث في كثبر الاحياتن عندما يفقد شخص يومياً أجزاء من حياته لن يعثر

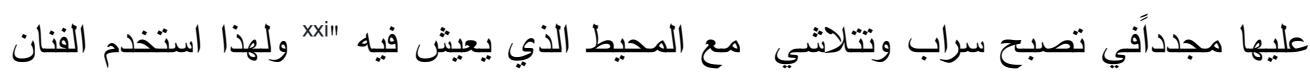
حذف الكتلة ليحدث نوع من الثفافية لتعبير عن مضمون التلاشي في الغربة. 
العدد الثاني عشر / المجلد الثاني المجلة العلمية بحوث في العلوم و الفنون النو عيه

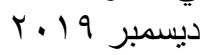

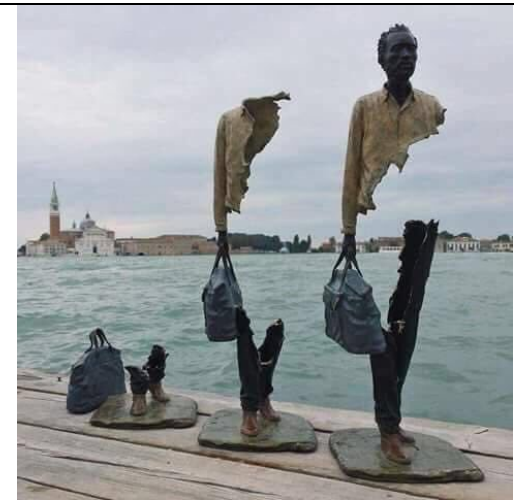

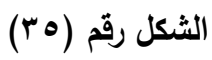

(منحوتات تلاشي في الغربة) ،للفنان (برونو كاتالانو)(الفرنسي ، علي شواطئ مرسيليا

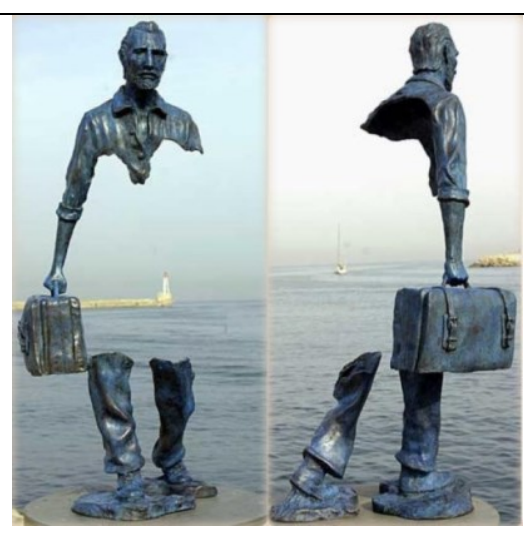

الثكل رقم (ع (ب)

(منحوتات تلاشي في الغربة) ،للقنان (برونو

كاتالانو)(القرنسي ، علي شواطئ مرسيليا

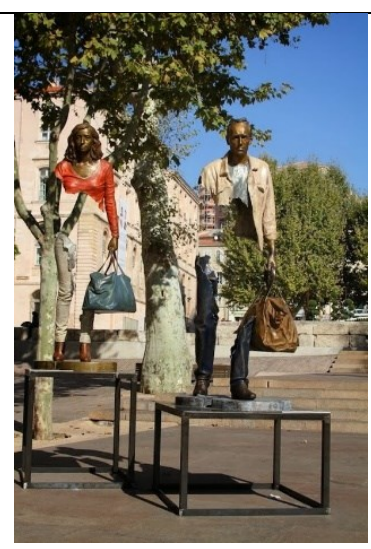

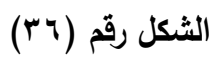

(منحوتات تلاشي في الغربة) ،للفنان (برونو كاتالانو)(الفرنسي ، علي شواطئ مرسيليا 


\section{هـ الثفافية الايهامية عن طريق الخداع البصري}

وهي شفافية تتحقق عن طري الايهام والحيل بأستخدام الخامات التشكيلية المعتمة،

وفيها يظهر الايهام بالثفافية هذا نوع يعتمد فيه النحات علي الابتكار في تقسيم الخطوط والمسطحات وتوزيعها، بشكل محسوب في محاولة لاستثمار ذلك التذبذب الناتج عن الادراك البصري (Moire Effect) ، لتحقق (الثفافية الايهامية) التي تعتمد علي الخداع البصري، والتغير في شكل الكتلة واحداث فراغات للايحاء بالتاثير الثفاف في العمل الفني والبحث

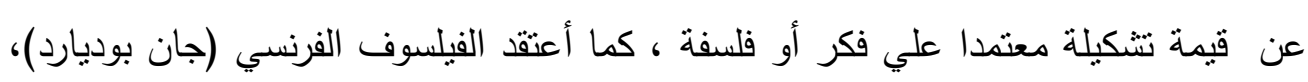
الذي وضح الأثر العميق للمعلومانية على كل من الفن والثقافة، والبحث من خلال تركيز الفنانين على (الايهامية والرمزية) في المعاني، وسعيهم للتخلب على المادية والتجسيم والحضور وسعى الفنانين الى اقامة علائق جديدة مع العالم المحيط، من اجل خلق الكثير من المؤثرات المكانية والفضائية، حيث تظهر معاني جديدة تسمح بتحرير وجهات النظر

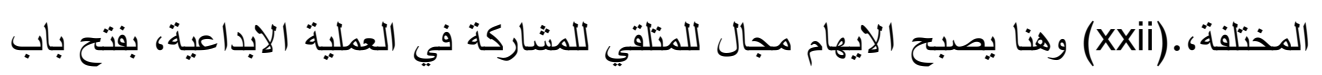
التأمل واعمال الخيال لاستتناج مضمون العمل الفني .

قد يخرج النحات عن مآلفه للمنلفي من مظاهر ، فيسعي لإيجاد حلول تشكيلية مبتكرة ، "

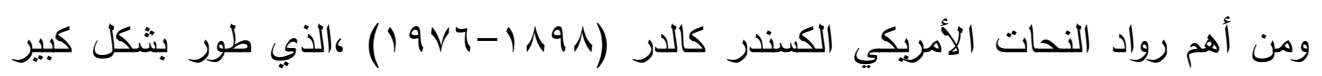
تثنيات النحت، وقد كانت قناعة كالدر في استخدام الأسلاك علي اعنبار أن كون النحت السلكي ذكيا و مبهجا، لكنه بعد ذلك أقر بأهمية الأسلاك في تاريخ النحت، وبأنها تمثل علامة فارقة، اظهرت امكانات عظيمة تكمن في السلك كخامة نحتية، ويشير كالدر بأن الأسلاك يمكنها أن تعرض عدة أثنياء في وقت واحد، لأن الثيء السلكي شفاف ولا يحجب فئه الأثياء الموجودة خلفه، و لكالدر بصمته الخاصة و أسلوبه، الي جانب التقنية التي تميزه عن غيره، كما أنه يعبر عن عالمة بأدواته الخاصة التي جعلت من كتلة العمل الفني الثفافة، 
وللفراغ المحيط أهمية كبيرة، تجزب العين لتبحث عن المنظور أو العمق للوصول إلي الفكر xxiii". x x الذي وراء العمل

وفي الثكل (rV) "يمكن أن شاهد صورة لكالدر، وهويقوم بتشكيل واحد من أعمالة بخامة السلك ، وقد تبين وجود نوع من الثفافية، التي تمكن المشاهد من رؤية أكثر من وجه في العمل الواحد ،وهذا يوضح لنا أنه يمكن بحساب المساحات وتثقيم وتوزيع الفراغ الجيد داخل

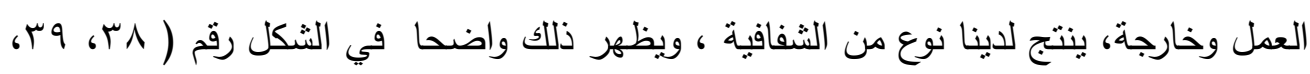

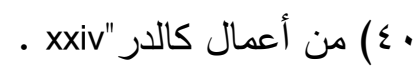

ويمكن أن نري نوع أخر من الثفافية الايهامية في الثكل رقم (اع، rع؛ rع) النصب التذكاري لنيلسون مانديلا، للفنان ماركو، سيانفانيلي ب ا ـ rم ومن الجدير للإثشارة إليه ان النحات في نموذجه هذا قد تمكن تقسيم المساحات، وتوزيعها حتي وصل إلي الايهام بوجود الثفافية التي خدمت النحات في عرض الموضع، حيث استعارهذه الثفافية في التعبير عن السجن والاعتقال الذي عان منه نلسون ماندلا ،" بأن كون العمل الفني من مجموعة من له

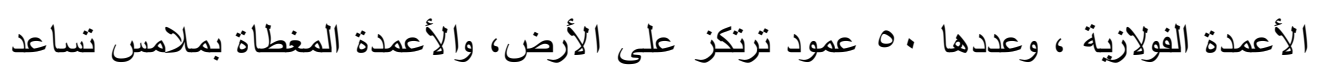
في تكوين صورة لوجه مندلا تظهر من خلف قضبان السجن الذي قضي به rV عاما بسبب جهوده لتحقيق المساواة في الحقوق.

ترك الفنان مساحة فراغ حوالي( 10 ( قدم)، أمام النحت حتي يتمكن المشاهد من

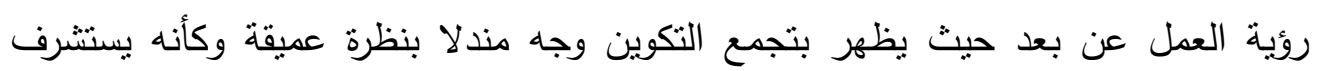

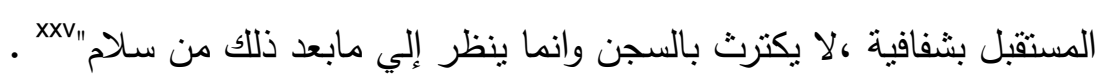

وترتيب المدروس المنتظم للاعمدة أعطي فرصة لروي مختلفة من معظم الزوايا ،

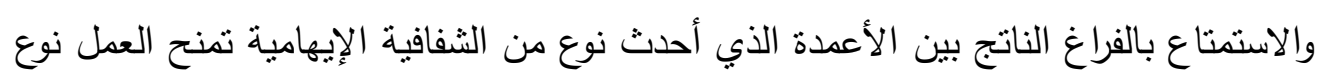


من خفة الكتله، ورقي وسمو العمل الذي حمل المشاهد علي الاقتناع بسمو ونبل شخصية مندلا ، حيث حارب سياسة الفصل العنصري، منذ عام ب 197 ، وعاني من العتقال والسجن سنين طويلة حتي أصبح رمزا وطنيا في بلده ، ورمز للنضال في العالم .

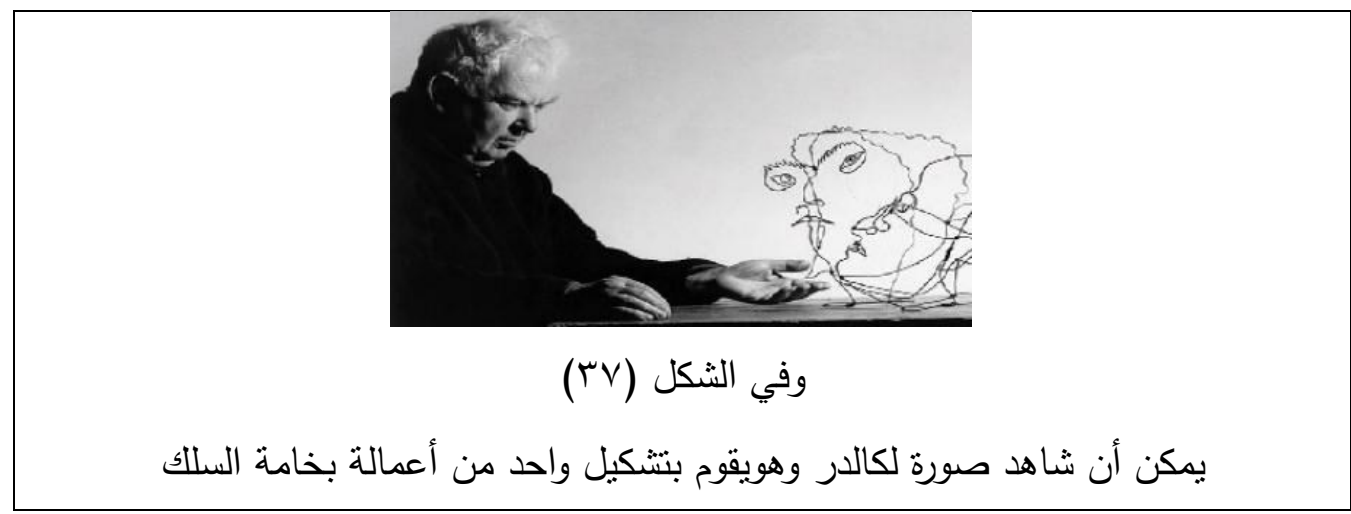

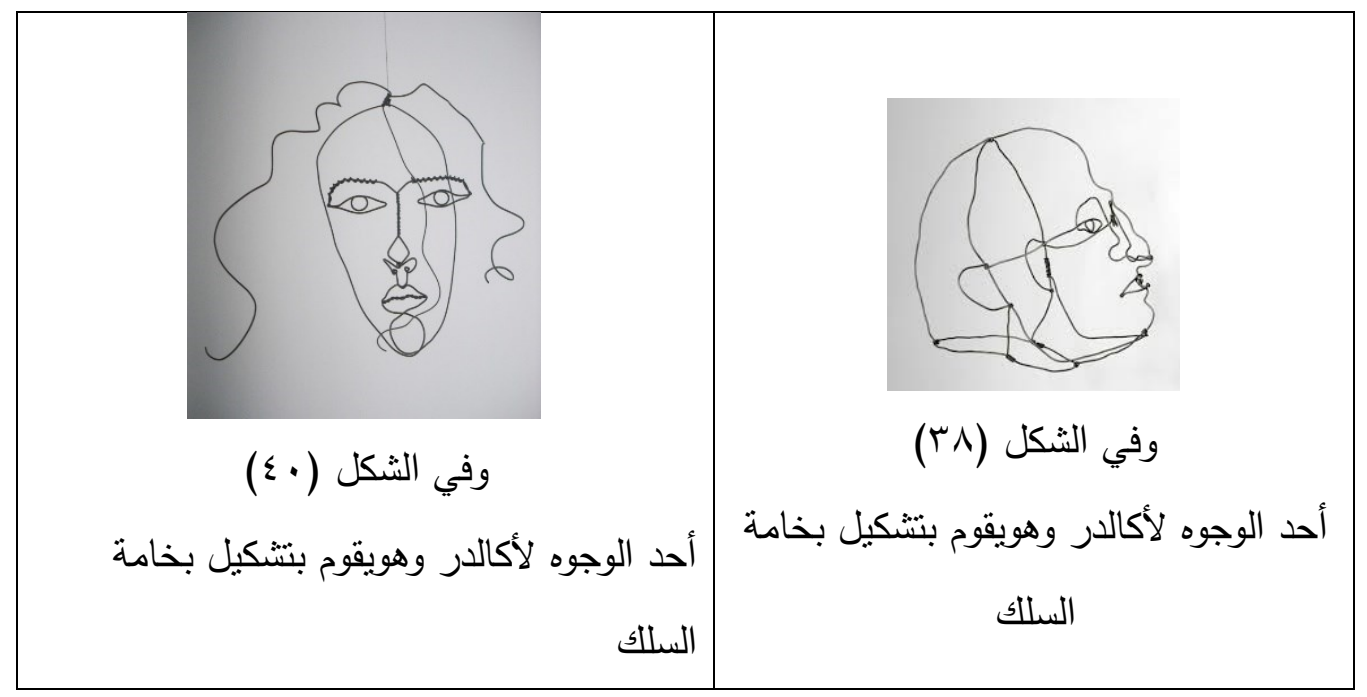




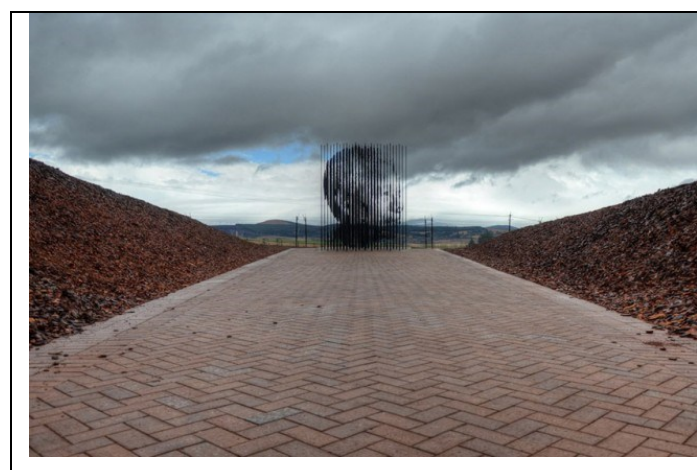

الشكل رقم (1) - (1) - (1)

نصب تذكاري( نيلسون مانديلا) ، لقنان ماركو، سيانفانيلي r I + r م -الخامة فولاز - يبلغ ارتفاعها

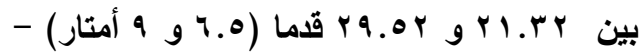

9. . في هويك، وهى مدينة تقع على بعد به

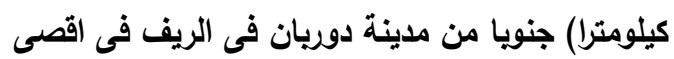

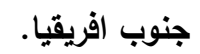

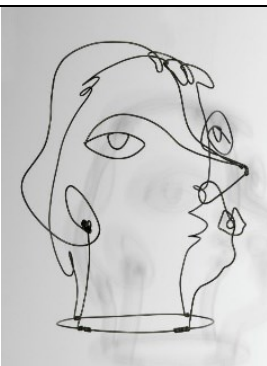

\section{وفي الثكل (q) - (ب)}

أحد الوجوه المزدوجة لأكالدر وهويقوم بتشكيل بخامة السلك

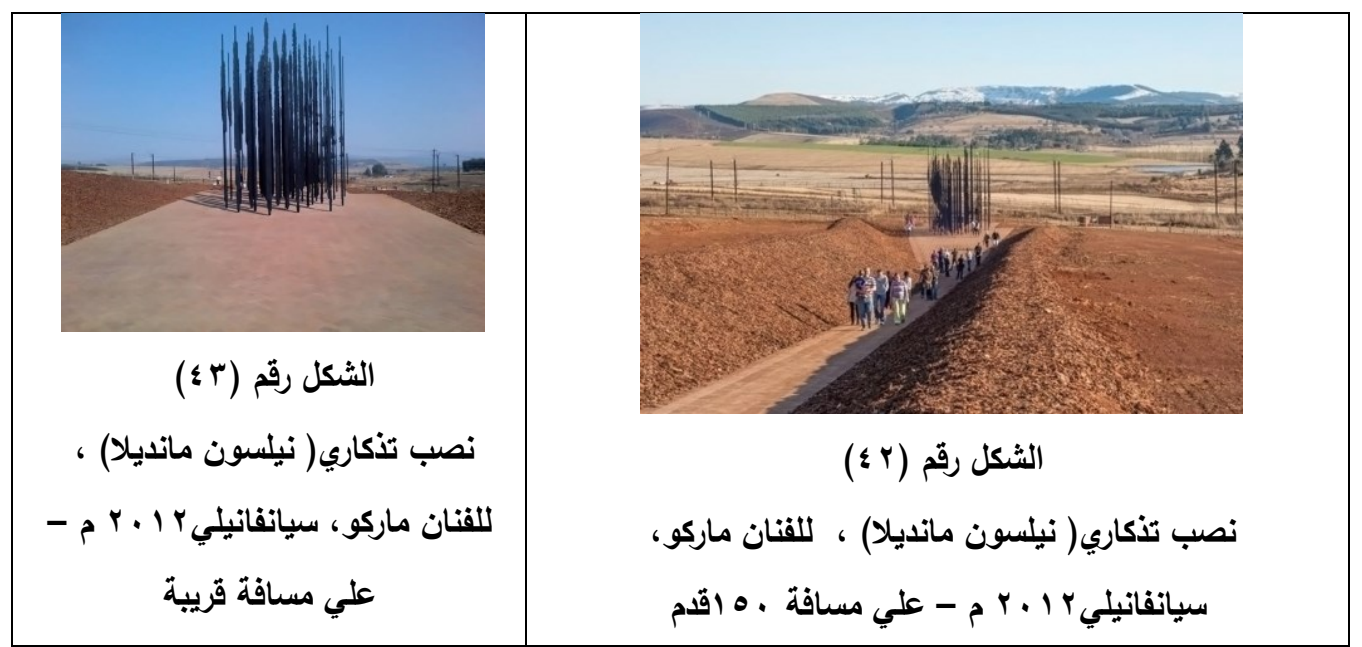




\section{ج- شفافية تحقيق عن طرق الحركة الفعلية}

ادرك كثير من الفنانين أن الطريق إلي العملية الابداعية لم يعد النظر في الطبيعة

فقط ، لكنه يلزم اتباع منهجية علمية موجه لـه، حتي يتمكن من الانتاج الإبداعي، لذا نجد

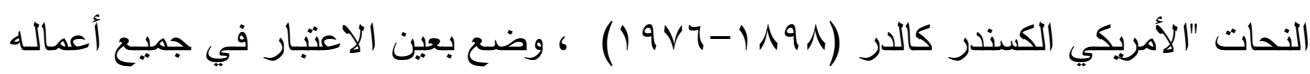
خاصية التوازن الهندسي للمنحونات، وقام بتطويع هذه الخاصية لتطوير منحوتاته المتحركة، جعل كالدر السيرك كمكان وشخوص موضوعا لكثير من اعماله، التي تبدو متدلية من سللك، او تتشكل بالاتحناءات والالتواءات للمـادة السلكية بما يجعلها تجسد شخصيات ( انيميشن ) متحركة"xxvi، حيث اهتم كثير بموضوع الحركة في النحت "،

كذلك نـاعوم جـابو بعبقريـة الفنـان أنتج أعمال فنيـة جديدة في تتاولها للمعطيات الفنيـة، باستخدام قيم تشكيلية غير مسبوقة، تحقيق الثفافية عن طريق الحركة الحقيقية في العمل • الفني

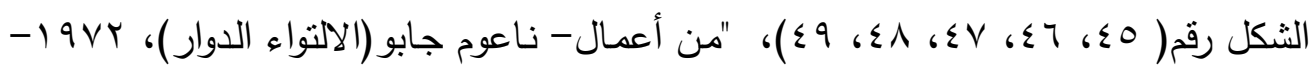
r 19V1 - الموقع مستشفى نوماس ، لندن - مصنوعة من لوحات الفولاذ المقاوم للصدأ؛ نحت حركي - نافورة ملتوية ، تعد من أهم المنحوتات التي تعتمد علي الحركة الفعلية" وبتأمسل العمل الفني نجد أن النحات قام ببنـاء العمل الفني ككيان هندسي ، معتمدا علي التوزيع المتتاسق للكتلـة النحتيـة مـع الفراغ، ولإستكمال جمال العمل الفني طور مفهوم بنـاء التكوين، باستخدام تلك الخطوط الناتجـة عن اندفاع المـاء في اتجهات محسوبة هندسيا، بحيث تصنع مع بعضها البعض مسطحات شفافة نظهر ماخلفها ، وفي نفس الوقت تتقاطع مـع بعضـها البعض، لينتج عنها شكلا جماليا محسوب بدقة، بحيث بستكمل بنـاء التكوين النحتي ،إلي جانب الحركات الرشيقة للماء ، والحركة الدائرية لجسم النفورة ، التي يصنعان حالة من الثفافية الايهامية عن طريق الحركة في هذا العمل، ولقد عكست موقفَ ناعوم 
جابو تجاه البنائية، فقد اهتم ناعوم جابو بإبراز البنائية الإنشائية في العمل النحتي، وهي تحمل صفة وخصائص الحركة، وفكرة توسيع قاعدة العمل النحتي إلى الفضاءات المجاورة.

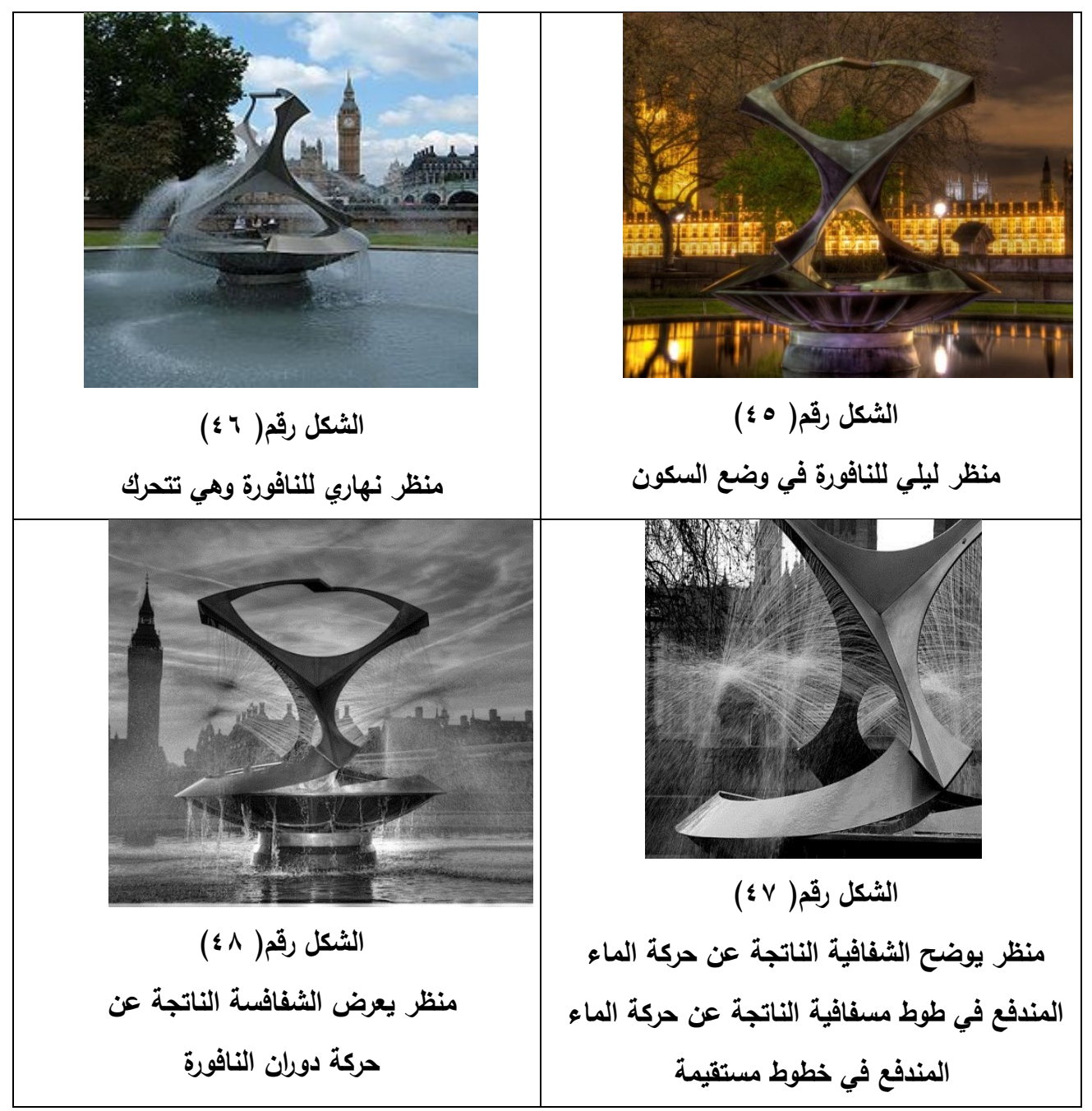




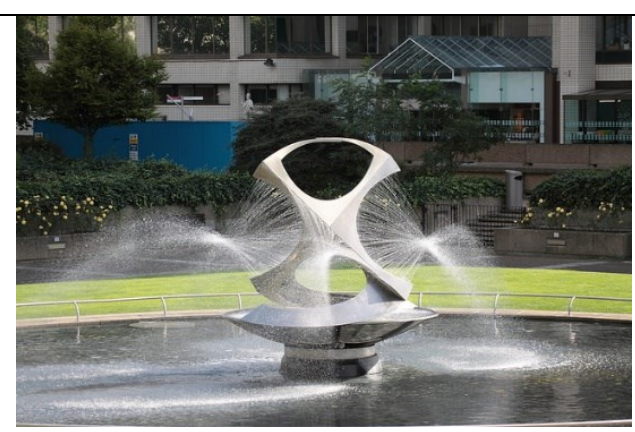

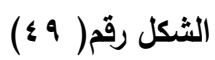

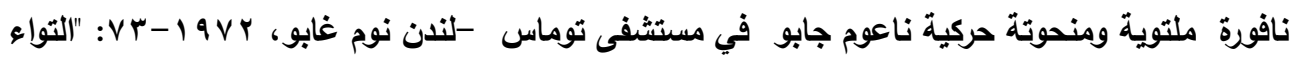
الاوار"، النحت الحركي / نافورة لوحات القولاذ المقاوم للصدأ منظر للنافورة اثثاء الحركة

\section{V- شفافية تتحقق من خلال الضوء والتحت الرقمي}

وبتطور التكنولوجي المتلاحق ظهر في عالم الفن استخدامات الضوء، كخامة بمكن للنحات استغلالها كواحد من أبواب التعبير ، ولان هذه الخامة بطبيعتها نورانية شفافة، فهي تعد نموذج جيد للثفافية في النحت ، ونجد في الثكل رقم (·O، (O)، ب0)، " منحوتة رقمية معلقة في السماء، للنحاتة (جانيت ايللمان Janet Echelman)- للاحتفال بمهرجان أضواء المدينة - قاعة المدينة بحديقة شتوبة - أمستردام - هولندا- بارتفع 180- 180في

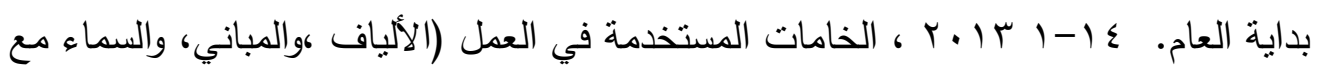
الإضاءة الملونة ، واي فاي ، وبرمجة الكمبيونز التفاعلية) ، يتم مزج الألياف مع النايلون و UHMWPE (البولي إثيلين عالي الوزن الجزيئي)، والعمل عبارة شكل غائمة ضخمة من طبقات من الألياف الضوئية ، مضفر ومعقود تضئ بألوان شفافة مبهجة ، التي تتغير مع تغيير الرياح والطقس لخلق الجو من الألوان المتموجة في الليل" Xxviii، وبنبض النحت بالحياة بالضوء الملون المتوقع، ونتبع الفنانه نمط دقيق لخلق نوع من الالوان الثفافة التي 
تظهر ما في السماء من جمال بشكل تفاعلي مع الجمهور الددعوون عن طريق، استخدام هواتفهم الذكية لتحديد الألوان، واستبعاد الأنماط بلمسة إصبع، مما بخلق تأثثرات تموج ليراها الجميع، والمنحوتة تعكس الضوء علي سطح الماء ، يدعوك العمل الفني للتوقف مؤقتًا وسط الصخب والاضطراب ، مما يوفر فرصة للتحديق في السماء، والتأمل في مظهر مادي للنزابط

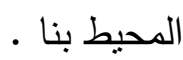

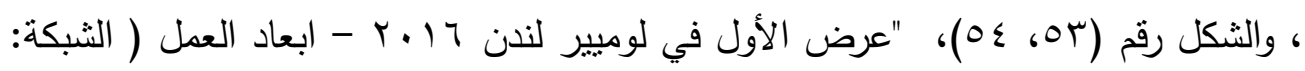

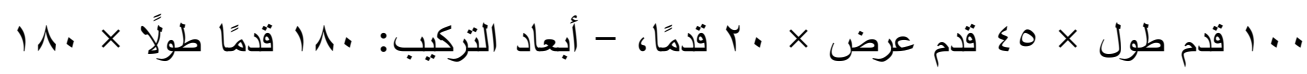

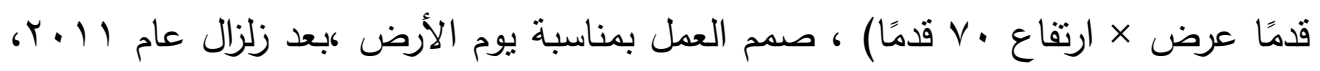
وتسونامي، استلهم شكل النحت من مجموعات البيانات الخاصة بآثار موجات تسونامي، التي تتنشر عبر المحيط الهادئ بأكمله" xxix.

والعمل الفني كمضمون متعلقنا ومترابطنا بعالمنا المادي المعقد، حيث أصبح شبكة متلاحمة ومترابطة لايمكن فصلها، فما بحدث في مكان يؤثز علي مكان أخر ، والبنية الثبكية للنحت

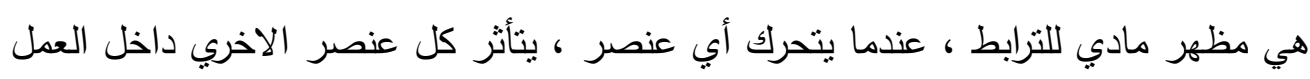

تتميز هذا المنحوت بالخفة والمرنة وامكانية نقلها من مكان إلي أخر حول العالم بعد ، إنها مصنوعة من الألياف تقنية التي تعد أقوى بـ 10 مرة من الفولاذ ، وتمزج الألوان المخصصة التي تجمعها مع الضوء الملون، وقامت الفنانة ببرمجة الالوان لإنشاء العمل الفني النهائي.

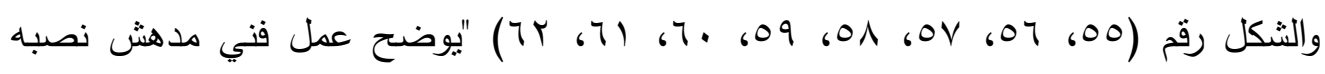
"النحات الإيطالي (إدواردو تريزولدي) في إحدى المناسبات الملكية في أبو ظبي، تبلغ 
مساحته . . . منز مربع، و تخطط دولة الامارة إلي أن يتم نقل هذه العمارة الثبكية الساحرة

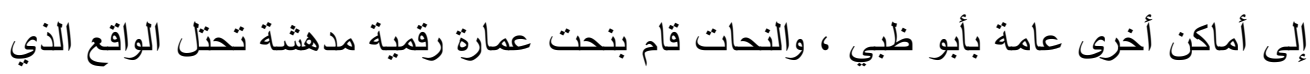
نعيش فيه، وتكسر الحاجز بين العالمين الواقعي والافتراضي ، فجعل من أعماله المعمارية نسخًا رقمية تتجسد بشكل ملموس على أرض الواقع! هذه هي نفسها المخططات، والنماذج الثبكية التي نعشق رؤيتها" xxx، لكنها هذه المرة ليست على شاثشة مسطحة، بل هي تحيط بك، وتسنطيع لمسها وتأملها من جميع الزوايا، " وهو لا يفعل هذا على نطاق ضيق، بل بملأ

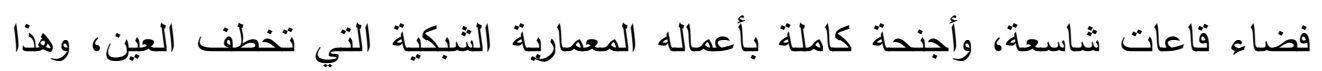
المزيج الغريب والرائع للعمارة الكلاسيكية القديمة، المتجسدة في الأعمدة ذات التيجان والأقواس والقباب مع التكوين الثبكي الأقرب للرقمي، والمرادف لعالمنا الحديث القائم على التقنية، ليس هذا فحسب، فإدورادو يدمج الكيانات المحيطة بشكل بارع مع معماره الشبكية ، كالأشجار

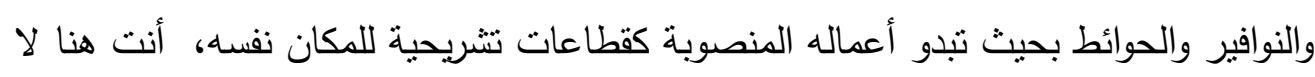
xxxi"تشاهد بُعدًا آخر عبر منظار سحري ... أنت بقلب هذا البعد نفسه 


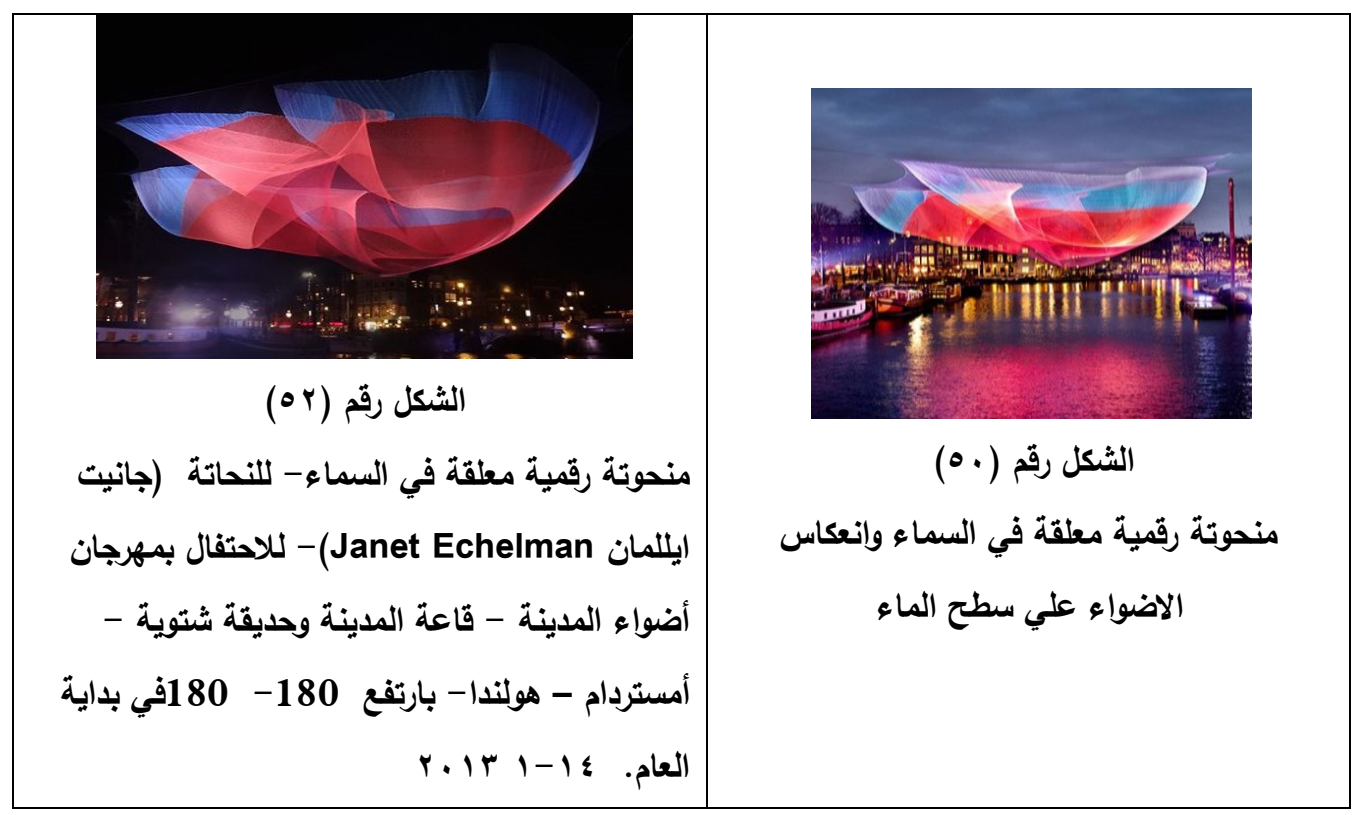

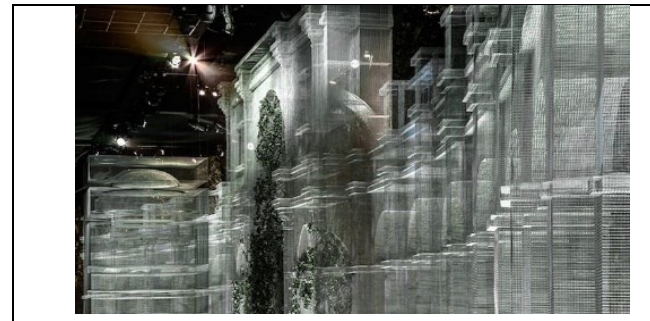

والثكل رقم (דهم)

صورة توضح تيجان الاعمدة والمقرنصات

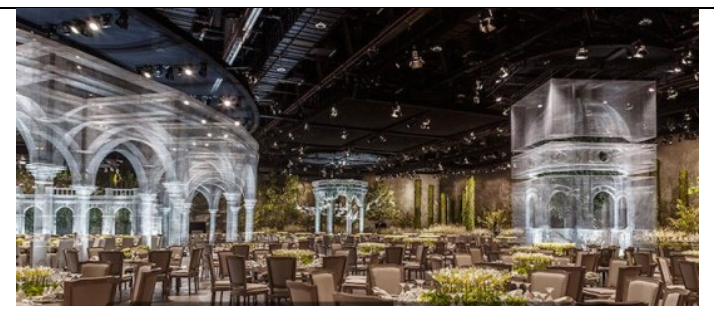

$$
\text { والشكل رقم (00) }
$$

"يوضح عمل رقمي نصبه "النحات الإيطالي (إدواردو" تريزولدي) في إحدى المناسبات الملكية في أبو ظبي، تبلغ مساحته . . . . متر مريع، و تخطط دولة الامارة إلي أن يتم نقل هذه العمارة الشبكية الساحرة إلى أماكن أخرى عامة بأبو ظبي 


\section{نتائج البحث:}

من خلال ماتقدم من دراسة تحليل الاعمال فنية يمكن من التوصل لما يأتي :1- تمكن النحات من التعبير بالثفافية لتوصيل فكرة الكمال في تجسيد البشري عبر تمثال فينوس وهو غاية في الروعة والجمال، ويكون قد حقق هدف النحات في تتحقق الثفافية من خلال تجسيد مظهر الثفافية في الخامات المعتمة مثل الرخام . ץ- استخدم النحات الوسائط الفيزيائية التي تتمتع بالثفافية الحقيقية، دون استخدام لايهام أوالحيل، وهي تلك الثفافية بمعناها الحرفي الذي نجده في الطبيعة من خواص تسمح بمرور الضوء، أو ورئية الصورة من خلالها ومع استعرض نماذج جابو بشكل عام تظهر لنا قدرته علي استخلال خصائص المواد الثفافة من خـلال عملية الدمج والربط بين المواد بطرق مختلفة من أجل إظهار حالات التفاعل بين الكتلة الثفافة والفراغ الثفاف r- تمكن النحات من تطويع الخامـة المعتمـة لتحقيق نوع مختلف من الثفافية خـل التشكيل بالنسج المفرغ ونري (بربارا ليشـا )النحاتة الاسترالية انها تلجأ لهذا الاسلوب في استخدام للتعبير عن عمق وتعقد المشاعر الانسانية ، وتهدف الفنانه تحقيق العمق المتصـل والمستمر ، بمعني أن يكون الثـكل مرئيـا بطريقـة جديدة بتحطيم الحـواجز المرئية للشكل التقليدي.

ع - ـ ويحقق النحات (برونو كاتالانو)الفرنسي الثـفافية التعبيريـة مـن خـال اعمالـة الفنية (منحوتات تلاشي في الغربة) ، حيث تلعب الثفافية في العمل الفني دورا مهما ، وابتكر النحات اسلوب حذف جزء من الكتلة ليظهر ماخلفة من منظر، لتعبير عن فكرة التلانشي والضياع ، لتكون بمثابـة المثير و محرك طاقي للتعبيريـة كامنـة ، تلك الطاقة التي أعطت حسا خاصا للخامة واخرجتها من دورها المعتاد أو شكلها المتعارف 
عليه إلـي والجود مـن جديد ، وكأنها اكتتففت من خـلال رؤيـة وإبداع للنحات الذي أعطاها طاقته التعبيرية خاصة به .

0- تمكن النحات مـاركو، سيانفانيلي مـن خـلاص النصب التذكاري لنيلسون مانديلا، تحقيـق شـفافية ايهاميـة عن طريـق استخدام الخداع البصـري يعتمد في ذلك علي الابتكار في تقسيم الخطوط والمسطحات وتوزيعها، بشكل محسوب في محاولـة لاسـتثمار ذلك التذبـب النـاتج عـن الادراك البصـري (Moire Effect) ، لتحقـق (الثفافية الايهامية). צ- اتسع مفهوم اقتران الفن بالعلم ، وضع بعين الاعتبار التوازن الهندسي للمنحوتات واستغلت القوانين، والنظريات العلمية، بشكل كبير في النحت الحركي، وقدم النحات ناعوم غابو "واحدة من أجمل منحوتات النحت الحركي،( النافورة الملتوية) التي تحققت فيها الثفافية عن طريق اندفاع الماء في خطوط هندسية محسوبة، مع الحركة الدائرية لجسم العمل V- وطـور النحـات ادئـهـ مـع التطـور التكنولـوجي المتلاحـق ظهر في عـالم الفـن استخدامات الضـوء كخامـة و استخلالها كواحد مـن أبواب التعبيز، ، ولان هذه الخامـة بطبيعتها نورانية شفافة فهي تعد نموذج جيد للثفافية في النحت ، مما تبع ذلك من ظهور المنحوات رقمية الاكثر ابهارا ، كما فعل النحات الإيطالي (إدواردو تريزولدي) في إحدى المناسبات الملكية في أبو ظبي ، الذي أقام عمل رقمي مدهش تبلغ مساحته

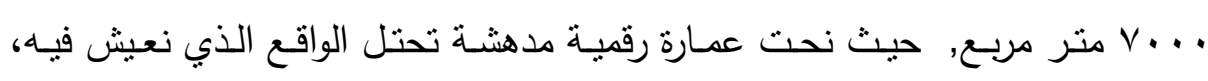
وتكسر الحاجز بين العالمين الواقعي والافتراضي ^- تفرد كل عمل من الأعمال المختارة في نتاول الثفافية بكيفية مختلفة، واسلوب خاص بالفنان من إمكانيات التشكيلية فكر ابداعي ، فظهر تتوع في اداء النحانين 


\section{اثري علم الفن التشكيلي بالعديد من الابدعات الفنية}

9 - ظهر تتوع في الأداء والتعبير والمعالجة الثقنية طبقا لمعطيات الخامة المستخدمة

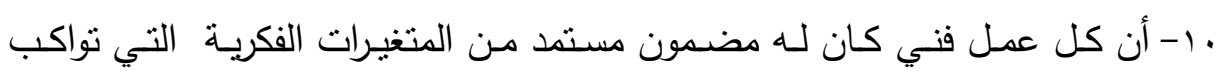

عصره 


\section{المراجع}

\section{أولا : المراجع باللغة العربية}

1 - أمهز ، محمود 997 ا : التبارات الفنية المعاصرة ، شركة المطبوعات للتوزيع والنشر،

$$
\text { طا، بيروت، لبنان }
$$

r- بسيوني - محمود r . . r : الفن في القرن العشرين ، الهيئة المصرية العامة للكتاب

$$
\text { ة، القاهرة }
$$

r- بوكدال ، إلسا ماريا ا . . T : العالمية وحوار الذاتيات في الفن ، ندوة علمية ، إعداد ، يوسف عايدابي،ترجمة:التيجاني حسب الرسول و حصة الياسي،دائرة الثقافة

$$
\text { والإعلام ، الثارقة }
$$

ع- حسن ، سليمان محمود || • بام :دور الخامات البيئية في النتكيل الفني ، كلية

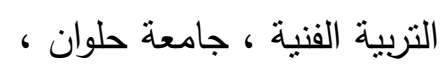

0- خليل - سيدة محمود احمد . . . ץ م : الابعاد الجمالية والتقنيية لاستخدام ضوء

الليزر في النحت الحديث ، بحث غير منشور رسالة ماجستير ، كلية تربية فنية ،

$$
\text { جامعة حلوان }
$$

7- رزق ،هاني محمد 997 1: اهمية الثفافية في التصوير كطريقة لاثراء التدريس بكلية التربية الفنية ،بحث غير منشور ،رسالة ماجستير ، كلية التربية الفنية ، جامعة

$$
\text { حلوان }
$$

V- عطية، محسن محمد ه . . rم: تذوق الفن "الأساليب ـ التقنيات ـ الدذاهب"، دار

$$
\text { المعارف، القاهرة }
$$




\section{ثانيا : المراجع باللغة الاجنبية}

8-Read h Acanise 1990: History of Modern Painting New York, Van Notre and Reinhold

9- Cited in International Handbook on Giftedness, Larisa V. Shavinina (2009),

ثالثا : الشبكة العنكبوتية

10- http: // faculty . ksu . edu . sa / pages / article $-r \cdot \mid V-1 r-V$

11-https://www.syr-res.com/article/2652.html 24-7-2014

12-1 https://abunawaf.com 2-2-2018

13- https://ochendaje.livejournal.com/785652.html 2-1-2018

14 - http://www.aljarida.com/articles/1500306443577536900 13-3-2018

15- https://lichabarbara.files.wordpress.com/2009/09/licha_7-from-

$15-12-2017$

16 - https://sooqbh.com/tag/\%D8\%B9\%D8\%A7\%D9\%84\%D9\%85-

\%D8\%A7\%D9\%84\%D8\%A5\%D8\%A8\%D8\%AF\%D8\%A7\%D8\%B9/page/17 295-2017/

17- https://ichabarbara.files.wordpress.com/2009/09/licha_7-from-

99-_2012_cm-38-x-37-x-34-b.jpg 3-3-2018

$18-1$ http://www.alriyadh.com/939098 15-12-2017

19 - http://www.althawranews.net/archives/13-3-2018

20-https://www.pinterest.com/pin/575897871089153703 13-3-

$201811-$

21-http://www.althawranews.net/archive 3-12-2017

22- 1 http://www.althawranews.net/archives/98942--- 5-12-2017

23- 1 https://en.wikiquote.org/wiki/Naum_Gabo 5-12-2017 
العدد الثاني عشر / المجلد الثاني المجلة العلمية بحوث في العلوم و الفنون النوعيه

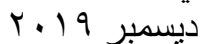

24- ' https://www.pinterest.co.uk/pin/335518240973168558 $-12-3-2018$

$25-$ ' http://www.echelman.com/project/1-8-london $\quad 12-3-2028$

26- ${ }^{\text {http://now.eljazeir.com/2017/05/24 }}$

27- http://www.ibda3world.com/wp-content/uploads/2017/05/IW-

Mesh-32-750x500.jpg 12-3-2018 
العدد الثاني عشر / المجلد الثاني المجلة العلمية بحوث في العلوم و الفنون النو عيه 